\title{
La desaparición del sistema municipal
}

\author{
Guillermo Lago Núñez \\ Secretario de Administración Local con habilitación estatal \\ en ejercicio en el Ayuntamiento de Roquetas de Mar (Almería)
}

SUMARIO: 1. EL CONTEXTO GLOBAL. 1.1. Globalización y autonomía local.- 1.2. Carta europea de Autonomía Local.- 2. EL RÉGIMEN ESTATAL DE ADMINISTRACIÓN LOCAL. 2.1. Situación del Régimen Local en España. 2.2. La superación de la garantía institucional de la autonomía local. 2.3. La participación de los entes locales en la elaboración de las normas.- 3. EL RÉGIMEN LOCAL Y LOS ESTATUTOS DE AUTONOMÍA DE SEGUNDA GENERACIÓN. 3.1.El nuevo paradigma. 3.2. El Régimen Local en el Estatuto de Andalucía.- 4. LA GOBERNANZA COMO SOLUGIÓN A LA "CRISIS DE GOBERNABILIDAD".- 5. NOTAS PARA UNA LEGISLACIÓN DE AUTONOMÍA LOCAL. 5.1. Una administración eficiente. 5.2. Una administración transparente. 5.3. Una administración sin trabas. 5.4. Una administración sin cargas. 5.5. Algunas propuestas.- 6. CONCLUSIÓN

A Manuel Zafra Víctor.

«El mundo se ha quedado sin alrededores, sin márgenes, sin afueras, sin extrarradios».

Daniel Inneraty, La Sociedad Invisible.

\section{RESUMEN:}

El presente trabajo analiza la situación del Régimen Local en el contexto de la interiorización o subconstitucionalización que se está llevando a cabo en los Estatutos de Autonomía de segunda generación. Se analizan los riesgos de encapsulamiento y cosificación del actual sistema proponiendo, ante la actual reforma del régimen local en Andalucía, una profunda transformación del mismo en el contexto de la globalización o «glocalización» que está acaeciendo en el ámbito internacional. 
Palabras clave:

Autonomía local, globalización, Estatutos de Autonomía, Régimen Local, Administración Pública, gobernanza.

\begin{abstract}
:
This paper analyzes the situation of Local Government in the context of the internalization which is being carried out in the second generation of the spanish Autonomous decrees. It discusses the risks of encapsulation and reification of the current system over the actual reform of local government which is taking place in Andalusia, addressing a profound transformation of its proceeding in the context of globalization or "glocalization" in the international arena.
\end{abstract}

Key words:

Local autonomy, globalization, Autonomous decrres, Local Government, Public Administration.

\title{
1. EL GONTEXTO GLOBAL
}

\subsection{Globalización y autonomía local}

Asistimos a lo que se ha denominado un lento declinar del paradigma de Westfalia, en el que el orden internacional se basaba en estados-naciones que ostentan todos los derechos y deberes de forma absoluta. De hecho se ha señalado que nos encontramos al comienzo del cambio más dramático en el orden internacional desde que en 1648 se firmó este Tratado [43].

En la actualidad una constelación de actores (grupos de intereses comunes, corporaciones transnacionales, organizaciones no gubernamentales, instituciones, tribunales y arbitrajes internacionales) así como multitud de acuerdos multilaterales, reflejan una transición desde el derecho internacional hasta ahora vigente a lo que se viene denominando derecho transnacional (transnational law) [9] del que, tal vez, el concepto Europa como construcción -la última utopía política según Ulrich Beck- sea su ejemplo más relevante. Pero estamos entrando en ésta nueva era con ideas, líderes e instituciones configuradas para un mundo de hace varios siglos, con una forma antigua [43] de ver ${ }^{1}$ y pensar.

\footnotetext{
${ }^{1}$ «To see the world this way, as a ceselessly complex and adaptative system, requires a revolution. It involves changing the role we imagine for ourselves, from architects of system we
} 
Resulta paradójico que los poderes locales, la autonomía local o gobierno autónomo local constituya, en el ámbito internacional, un término básico, una categoría política de uso común en el fenómeno de la globalización, de debate en las organizaciones supranacionales. Autonomía local, descentralización, libre administración, principio de subsidiariedad, democracia representativa y participativa, democracia real constituyen en esta línea, términos equivalentes.

Se apunta que su aceptación y asunción se debe a diversas causas. Se ha expuesto que la autonomía local no compite con la globalización [12] (La autonomía local, en tanto categoría jurídico-política que potencia el poder de las unidades políticas más pequeñas, más cercanas a los ciudadanos, ofrece una compensación positiva frente al alto grado de desarraigo jurídico-político (deslocalización) del fenómeno globalizador) antes bien coadyuva a la extensión del fenómeno globalizador.

En este sentido lo local es un contrapeso político necesario a la multinacionalización del nuevo sistema, y la superación de la fragmentación propia de lo local se efectúa mediante formulas de redes, hermanamientos, partenariados, asociaciones y conferencias de gobiernos locales; intereses comunes, en fin, entre ciudades y colectividades.

La universalización de la descentralización no puede entenderse de momento como una retirada del Estado. Aunque se aprecia una metamorfosis del Estado hacia formas cooperativas, en un proceso de una transformación: el que va desde el gobierno directo, central y soberano a organizador y cooperador [29]; en expresión de Schuppert el Estado garantizador que parte del reconocimiento de que: «el Estado no es quien decide y produce, sino más bien el que activa y modera los desarrollos sociales que ni puede ni debe determinar en exclusiva».

El auge de lo local también obedece a aspectos culturales, antropológicos, arraigado a veces en conceptos tribales, incluso puede que constituya un ar-

can control and manage to gardeners in a living, shifting ecosystem. For hundreds of years now we have lived in our minds as builders: constructing everything from nations to bridges, heedlessly grabbing whatever resources we'e needed in pursuit of a dream of some imagined palace of global prosperity. This mode of existence, which delivered amazing progress, is no longer suitable. The world is too complex, its resources too limited, and its internal dynamics too unstable to accommodate much more of this mania. It is now delivering the opposite of what we intend even as it presents us with new and insoluble problems. In a revolutionary age, with rapid change around us, our architects'tools are deadly. It is time for us to put them down and follow Hayek' injunctions to live and to think as gardeners.». 
quetipo humano. En cuanto que es lo local, donde desenvolvemos nuestra actividad vital, algo material, perfectamente identificable, no constituye una construcción artificial, una idea o elemento abstracto de referencia. Es el nivel donde surge y se desarrolla el contrato social.

En las ciudades se va a producir el $90 \%$ del crecimiento demográfico mundial hasta el año 2030, a finales de 2010 la población mundial será urbana al acoger al 50,5\% de la población planetaria, cuando este año termine $1.200 \mathrm{mi}$ llones de personas vivirán ya en ciudades de 100.000 habitantes equivalente a la tercera parte de la población urbana mundial y hay 600 millones que lo hacen en centros urbanos de hasta medio millón según datos de la División de población de la ONU. Es la ciudad, por tanto, el espacio donde ha de hacerse efectiva la convivencia intercultural, la integración social, la inclusión, la participación y, en definitiva, la cohesión social. Un ámbito que pasa de ser espacial (o territorial) a social para definirse como «el marco en virtud del cual podemos percibir y organizar todo aquello de lo que debemos responder» [29] o, tal como describe Innerarity: «Las acciones locales producen cada vez más efectos externos en otras comunidades, la política local queda trabada con el exterior, los procesos de globalización configuran nuevos espacios regionales. Todo ello conduce a que las tareas públicas ya no se puedan realizar dentro de los límites institucionales. Los gobiernos y las administraciones tienen que colaborar con los agentes económicos, los mercados ya no funcionan sin una cierta regulación estatal o sin sistemas de negociación institucionalizados y, en general, las instituciones están cada vez más comprometidas con sistema de coordinación. El gobierno de estas relaciones complejas y la gestión de tales interdependencias exige formas de cooperación, además de los tradicionales procedimientos, como la legislación ola asignación de recursos financieros».

Superada ya la visión de la Administración Local como una mera subdivisión burocrática del Estado, agente del Estado o corporación pública, aunque ciertamente aún no se vea. Lo local representa ahora la comunidad en una forma más concreta que en el nivel nacional, y a diferencia de otras identificaciones colectivas como la raza, la religión, o el origen étnico, supone compartir un conocimiento y una forma [9] de vida².

2 The unique legal structure of localities and their singular traits enable them to capture human imagination like no other entity. Even when big, pluralistic, and multicultural, localities suggest the possibility of imagining a community in a more concrete form than extant at the national level. Indeed, if every group identity is always somewhat imaginary, what de nes the locality as an imagined community is that it is still grounded in daily experience. Unlike other 
Pese a que el término descentralización parezca intrínsecamente democrático, debemos estar alerta ya que puede ser degradado -o lo está siendopor las normas oligárquicas impuestas por incontables élites territoriales con intereses espúreos. Solamente si el gobierno local incluye representantes elegidos democráticamente, los residentes participan de forma efectiva en la toma de decisiones - en lugar de sólo votar cada cierto período de tiempo-y, los valores, la innovación y el conocimiento local constituye el principal elemento de las mismas, se puede evitar esta degradación.

\subsection{Carta europea de Autonomía Local}

La Constitución municipal europea. Se ha dicho que la Carta europea de Autonomía Local es una Constitución de la autonomía local en el continente europeo [4], en realidad constituye un Tratado internacional singular cuya gestación, en el seno del Consejo de Europa, se inicia con la creación el 27 de septiembre de 1952 de una Comisión de Asuntos Municipales y Regionales culminando con la apertura a la firma de los Estados miembros el 15 de octubre de 1985 y su entrada en vigor el 1 de septiembre de $1988^{3}$.

Lo cierto es que esta norma comunitaria está inspirando otros documentos de similar alcance como la Carta de la Autonomía Local Iberoamericana promovida por la Organización Iberoamericana de Cooperación Intermunicipal o la Carta Mundial del Gobierno Local Autónomo que está elaborando la Unión Internacional de Poderes Locales (IULA). Tiene, de acuerdo con lo establecido en el artículo 94.7 de la Constitución española eficacia jurídica interna automática.

Si queremos conocer cuál es la definición de Autonomía Local debemos referirnos al artículo 3 de la Carta que entiende por autonomía "el derecho y la

collective identifications, however, belonging to a locality is based not on race, religion, gender, ethnicity, or other inherited traits but on shared knowledge and a shared way of life. The era of globalization both threatens to destroy, and promises to rescue, this unique collectivity.

${ }^{3}$ La ratificación por España, el 20 de enero de 1988 (BOE núm. 47, de 24 de febrero de 1989) que entró en vigor el día 1 de marzo de 1989, por la que se declara que la Carta europea de la Autonomía Local se aplicará en todo el territorio del Estado en relación con las colectividades contempladas en la legislación española de régimen local y previstas en los artículos 140 y 141 de la Constitución incluye la siguiente salvedad: "No obstante el Reino de España, únicamente no se considera vinculado por el apartado 2 del artículo 3 de la Carta en la medida en que el sistema de elección directa en ella previsto haya de ser puesto en práctica en la totalidad de las colectividades incluidas en el ámbito de aplicación de la misma”. 
capacidad efectiva de las Entidades Locales de ordenar y gestionar una parte importante de los asuntos públicos en el marco de la Ley, bajo su propia responsabilidad y en beneficio de sus habitantes",y ello sobre la base expuesta en el Preámbulo de que las Entidades Locales son uno de los fundamentos principales de un régimen democrático y que el derecho de los ciudadanos puede ser ejercido más directamente en una administración a la vez eficaz y próxima al mismo, lo que se viene a reconocer como principio de subsidiariedad o proximidad en el siguiente sentido: "el ejercicio de las competencias públicas debe, de modo general, incumbir preferentemente a las autoridades más cercanas a los ciudadanos. La atribución de una competencia a otra autoridad debe tener en cuenta la amplitud o la naturaleza de la tarea o las necesidades de eficacia o economía".

Conviene hacer una breve consideración sobre el principio de subsidiariedad en la esfera local - al que se ha denominado la clave de bóveda del sistema competencial comunitario- en relación con el principio de proporcionalidad. El debilitamiento de éste último, como canon de delimitación de competencias, se debe a que su utilidad se ha demostrado más en la defensa de las libertades comunitarias o en la protección de los intereses particulares en recurso de anulación que como principio de competencias de poderes públicos, limitándose, a complementar el principio de subsidiariedad sólo para determinar si se infringe o no el segundo. Para de la Quadra-Salcedo [20] la fórmula más poderosa de la Ley 7/1985 en garantía de la autonomía local es la que se contiene en el artículo 2 en la medida en que por primera vez se recoge en nuestro Derecho el principio de subsidiariedad al establecer el mandato de asignación de competencias a los Entes Locales por el Estado y por las Comunidades autónomas de acuerdo con criterios objetivos adelantándose a la Carta Europea de la Autonomía Local.

Como fórmula sustituta del principio de proporcionalidad en materia de defensa de la autonomía local se han propuesto otros métodos o técnicas aplicativos [42], a los que parece señalar la Carta aunque sin mencionarlos, como es la ponderación. Señala Sarmiento Ramírez, siguiendo a Rodríguez de Santiago y a Alexy, que la ponderación como método se escalona en tres fases: en primer lugar se identifican los bienes, valores e intereses en conflicto, en segundo lugar, se les atribuye un peso o importancia a cada uno y, en tercer lugar se analiza el equilibrio conforme al criterio siguiente: "cuanto mayor sea el grado de perjuicio a uno de los principios, mayor ha de ser la importancia del cumplimiento de su contrario", de lo que surge un resultado que debe contar con una presunción de legalidad a favor del Ente demandado.

Por último hay que significar que la definición de la autonomía recogida en la Carta europea no es nominal al concebirse como una capacidad efectiva, 
no se limita a la gestión, sino que alcanza la ordenación o regulación, y se refiere, en cuanto a su objeto, a una parte importante de los asuntos públicos cuya ejercicio se efectúa bajo la propia responsabilidad de las Entidades Locales.

Antes de emprender cualquier regulación de Régimen Local se debe efectuar una lectura en profundidad de los apartados que se contienen en la Primera parte de la Carta, o contenido sustantivo, que regula el fundamento constitucional de la autonomía local (artículo 2), su concepto y alcance (artículo 3 y 4), la protección de los límites territoriales de las Entidades Locales (artículo 5), la adecuación de las estructuras y medios administrativos a sus cometidos (artículo 6), las condiciones de ejercicio de las responsabilidades a nivel local (artículo 7), el control administrativo de los actos de las Entidades locales (artículo 10), la protección legal de la autonomía local (artículo 11).

La supervisión y control en la Garta europea de Autonomía local. Uno de los aspectos más controvertidos de la Carta europea es el artículo 8 relativo al control administrativo de los actos de las entidades locales que se expresa en los siguientes términos:

1. Todo control administrativo sobre las Entidades locales no puede ser ejercido sino según las formas y en los casos previstas por la Constitución o por Ley.

2. Todo control administrativo de los actos de las Entidades locales no debe normalmente tener como objetivo más que asegurar el respeto a la legalidad y de los principios constitucionales. Sin embargo, tal control podrá extenderse a un control de oportunidad, ejercido por autoridades de nivel superior, respecto de las competencias cuya ejecución se haya delegado en las Entidades locales.

3. El control administrativo de las Entidades locales debe ejercerse manteniendo una proporcionalidad entre la amplitud de la intervención de la autoridad de control y la importancia de los intereses que pretende salvaguardar.

El impacto administrativo de las funciones de supervisión y control fue objeto de un interesante trabajo en el marco de la Unión Europea (1996 (CPL (3)7 Rapporteur: Georgio de Sabbata basado en una investigación efectuada por Alain Delcamp). Y ello ya que al amparo del artículo 8 se puede producir una desviación del objetivo de la Carta y que, en lugar de una supervisión para asegurar el cumplimiento de las leyes y los principios constitucionales, se puede convertir en un mero y arbitrario control de oportunidad. Por ello es muy importante destacar el signifi- 
cado de competencias propias y competencias delegadas ya que en estas últimas cabría el control de oportunidad aunque la autoridad delegada pueda contar con ciertas facultades dispositivas conforme al artículo 4, párrafo 5 de la Carta.

Tal y como advierte el Grupo de Expertos independientes en la Carta europea de autonomía local en el análisis de los cuestionarios sobre nuevas formas de supervisión y control (Estrasburgo 9 de junio de 2005, GG/INS/GIE (12) se constata que puede existir un declinar del control estatal de oportunidad aunque se debe efectuar un seguimiento a los gobiernos regionales ${ }^{4}$.

La Carta Europea de Salvaguarda de los Derechos Humanos en la Ciudad. Como consecuencia de la reflexión de los poderes locales en la defensa y protección de los Derechos Humanos y coincidiendo con el cincuenta aniversario de la Declaración Universal de Derechos Humanos se celebró en Barcelona la primera Conferencia europea Ciudades para los Derechos Humanos. Un año después se presentó en la Segunda Conferencia celebrada la Carta Europea de Salvaguarda de los Derechos Humanos en la Ciudad a la que se han adherido más de setenta ciudades europeas, que asumenla obligación de incorporar en el ordenamiento local los principios y las normas, como también los mecanismos de garantía, establecidos en esta Carta; complementariamente, se comprometen a reconocer la Carta mediante la mención expresa de ella en sus ordenanzas; y, por otro lado, reconocen "el carácter de derecho imperativo general de los derechos enunciados en esta Carta y se comprometen a rechazar o denunciar cualquier actos jurídico, las consecuencias del cual serían un obstáculo para el cumplimiento de los derechos reconocidos o serían contrarias a su realización, y a actuar de forma que los otros sujetos de derecho reconozcan el valor jurídico superior de estos derechos".

Vemos cómo en el ámbito local se suscriben por las Entidades locales unos nuevos tipos de "tratado", en este caso, un instrumento esencialmente político

\footnotetext{
4 «There may, however, be some reasons for concern that newer forms of supervision and control are emerging. Paradoxically this may be the result of a general strengthening rather than a weakening of local or regional autonomy. Thus, it may be that, because more substantial functions have been conferred on local authorities, there is a greater central concern about the effcient (and, to a degree, uniform) delivery of services to citizens and aperceived need for greater supervision and control as a result. This may include additional financial controls introduced for the purpose of influencing local policy decisions or forms of centrally-driven 'best-value' supervision (or audit) with policy consequences. Equally, an expansion of the role of regional government between the central and local levels may result in an expansion of expediency controls by regional governments (perhaps seeking an expansion of their policy space) over local authorities. There may, in addition, be quite separate reasons in some countries for the growth of new forms of supervision and control that this questionnaire is intended to monitor so that, as a result, some general conclusions may be drawn.»
} 
y de carácter programático consistentes en convenios interadministrativos de ámbito transnacional, fuente exclusivamente de obligaciones entre las entidades firmantes, basado en el capacidad de vinculación convencional, incluso transnacional, de las entidades locales, que aspira a erigirse en elemento determinante de cada ordenamiento local.

En el caso de esta Carta es el fruto de un proyecto de cooperación local internacional emprendido de forma mancomunada por una serie de ciudades - en el marco de lo establecido en la Carta Europea de Autonomía Local (art. 10)-, que autoriza a los entes locales a cooperar internacionalmente siempre dentro del marco y de las condiciones que al respecto establezcan las leyes que comporta los siguientes efectos: a) un efecto horizontal entre las ciudades signatarias, b) un efecto vertical entre la ciudad firmante y sus propios ciudadanos, y, finalmente, c), un efecto horizontal entre los ciudadanos.

Directrices sobre descentralización y fortalecimiento de las autoridades locales. Dentro del Programa de las Naciones Unidas para los Asentamientos Humanos (ONU-Hábitat), se aprobó en Nairobi a finales de abril 2007, las Directrices sobre descentralización y fortalecimiento de las autoridades locales [40] como un instrumento fundamental para promover la buena gobernanza a todos los niveles y fortalecer a las autoridades locales, cuyos principios se inspiran en la Carta europea de Autonomía local siendo su objetivo básico apoyar y orientar la reforma legislativa cuando sea necesaria y procedente.

Dentro de las Directrices resulta interesante comprobar la relevancia que se otorga al principio de subsidiariedad que constituye la razón de ser del proceso de descentralización, conforme al cual las autoridades elegidas que estén más próximas a los ciudadanos deberán desempeñar las responsabilidades públicas (B.1.1) y en el que la intervención del gobierno nacional o regional sólo se producirá cuando éste no cumpla las funciones acordadas.

Las Directrices constituyen una autentica hoja de ruta de sobre las medidas legislativas y gubernamentales para el fomento de la descentralización y fortalecimiento de las autoridades locales no sólo en países de limitada descentralización sino para todos aquellos poderes que decidan adoptar medidas para el desarrollo sostenible de sus asentamientos humanos y se propone a este Grupo de Trabajo como punto de partida.

Por otro lado en estos momentos el Consejo de Gobierno de las Naciones Unidas para el Programa de asentamientos humanos ha ultimado una reso- 
lución o guía para el acceso a los servicios básicos cuyos ejes fundamentales son, como continuación de las anteriores Directrices, la transparencia, participación y gobierno efectivo, la descentralización y el rol de las autoridades locales en los procesos de asociación y determinación de las mejores prácticas para la prestación de los servicios [41].

\section{EL RÉGIMEN ESTATAL DE ADMINISTRAGIÓN LOCAL}

\subsection{Situación del Régimen Local en España}

\section{El mapa municipal}

La crítica al modelo. Queremos coincidir, en este trabajo, con gran parte de la posición expuesta por el profesor Parada Vázquez en relación con el mapa municipal [49] y la crítica a la tesis mantenida en el Libro Blanco del Gobierno Local, al que califica, con cierta gracia, de practicar en esta materia un «ecologismo administrativo». La justificación del modelo actual (según el Libro Blanco: «para alcanzar una mayor democracia») que en su origen tuvo algún sentido en un ambiente estático y campesino resulta compleja. El hecho de que no se hayan promovido las fusiones de municipios, y, sin embargo, se hayan creado nuevos bajo la competencia de las Comunidades Autónomas parece una aberración en un país abigarrado de minifundios municipales. En el caso de Cataluña a pesar del contundente Informe Roca Caldera y Moix, que puso de relieve datos escalofriantes: un total de 646 municipios catalanes tienen menos de 2.000 habitantes, lo que equivale al 6,07\% de la población catalana, pero ocupaban el $67,6 \%$ de la superficie, la propuesta de supresión de los pequeños municipios fue rechazada ${ }^{5}$.

\footnotetext{
${ }^{5}$ Como señala el profesor Parada: «La pervivencia del pequeño municipio ante las profundas transformaciones de la vida social y política de las últimas décadas hace que las justificaciones iniciales de su existencia no concurra en la actualidad, como tampoco se dan los contrapesos estatales en forma de controles gubernativos a esa orgía organizativa que suponía su crecido número. Si el pequeño municipio se justificaba en atender las necesidades de una estanca población campesina, como la administración de bienes comunales, los caminos, las fuentes, el abrevaderos, el cementerio, la escuela de un solo maestro y otras semejantes, en la actualidad, la mayoría de los municipios ni siquiera los más ínfimos, no necesitan esos servicios y reclaman otros de mayor entidad: transportes, enseñanza, servicios sociales, abastecimiento de aguas, cuya implantación no resulta rentable (.../...). En segundo lugar, el exorbitante número de municipios en Francia y en España no ofrecía graves riesgos de disfuncionalidad, en cuanto funcionaban a
} 
El profesor Parada justifica el mantenimiento de este mapa municipal en cuestiones partidistas derivadas de la conveniencia de contar con un número considerable de cargos electos, por una clase política que demanda más y más cargos, muchos de ellos recayendo en las mismas personas, que distribuyen los partidos mayoritarios. Puede ser éste, o cualquier otro, el motivo para no haber abordado ya una política pública racional que evite la proliferación de entidades locales en España, no sólo Ayuntamientos sino Entidades Locales menores, Cabildos, Diputaciones, Mancomunidades y otras formas organizativas como Consorcios de Entidades locales que se distribuyen y se superponen por todo el territorio español. En contraste con la situación española conviene recordar los ejemplos seguidos por otros países europeos a los que en el año 2010 se ha unido Francia 6 .

La subdivisión de la división. Llama la atención que la misma irracionalidad y desproporción en las divisiones de los términos municipales se produce dentro de cada término municipal en las subdivisiones en las que es competente cada entidad local, en parte consecuencia de las que se producen con ocasión de los procesos electorales, y que conforme a las normas estadísticas la numeración de las Secciones, cuando se produce cualquier división, no es correlativa y no se pueden renumerar las Secciones por lo que quedan Secciones geográficamente contiguas con numeración no correlativa.

modo de órgano desconcentrados en la tesis de su minoría de edad, y con cuánta razón. Pero ahora el pequeño municipio, menguado en habitantes y escaso de territorio, inhábil soporte para la prestación de servicios eficientes, se declara ente político soberano, emancipado del Estado y la Comunidad Autónoma, y, como los hijos consentidos, clama por mayores competencias e ingresos y no soporta control ni vigilancia algunos.»

${ }^{6}$ La República Federal Alemana, en los años 1965 a 1975, llevó a cabo una política de fusión reduciendo el número de las municipalidades de 25.000 a 8.414; Dinamarca, durante los años setenta, realizó una reforma radical de Administración local y redujo a una quinta parte el número de los municipios (concretamente, pasa de 1.387 a 275); Suecia, tras las medidas llevadas a cabo en el año 1952 y, más adelante, en el decenio 1962-1973, divide por diez el número de sus comunas (pasa de un total aproximado de 2.500 colectividades locales básicas a tan sólo 278); Grecia, a partir de la drástica reforma iniciada en el año 1998, consigue que sus municipios pasen de 5.343 a 1.033; Gran Bretaña, mediante las reformas realizadas durante el bienio 1974-1975, mengua sustancialmente la cifra de colectividades locales que de 1.520 se reduce a 522; Bélgica, merced al procedimiento de fusiones obligatorias establecido en el año 1975, minoría el número de comunas de 2.359 a 596. 
En efecto, la división del término municipal en distritos y secciones y las variaciones de los mismo corresponde a cada Ayuntamiento conforme con la Ley Reguladora de las Bases del Régimen Local ${ }^{7}$. Las Secciones son unidades pequeñas, que coinciden con las secciones electorales. Están basadas, de acuerdo con el artículo 23 de la Ley Orgánica 5/1985, de 19 de junio, del Régimen Electoral General, en un número máximo de dos mil electores y un número mínimo de quinientos, por lo que su plasmación espacial presenta una notable variedad de forma y tamaño.

De acuerdo con la Resolución de 9 de abril de $1997^{8}$ por la que se dictan instrucciones técnicas a los Ayuntamientos sobre la gestión y revisión del Padrón Municipal, existe una cierta equivalencia entre el número de electores establecido en la Ley Orgánica de Régimen Electoral y número de habitantes. Recomienda que el tamaño de la Sección no supere los 2.500 habitantes. Con este objetivo se dictan unas normas básicas para la participación de las Secciones que sobrepasen los 2.000 electores o de aquellos que superen los 2.500 habitantes debiendo contener las Secciones resultantes de la partición, al menos, 500 electores.

El Distrito es, en cambio, una unidad de grandes dimensiones, que abarca un número indeterminado de Secciones, absolutamente variables de unos municipios a otros y aún dentro del mismo municipio. Hay además municipios que tienen una tercera división denominada zona estadística, de tamaño intermedio (por ejemplo, Barcelona), y otros que tienen barrios, división igualmente de tamaño intermedio entre las citadas (por ejemplo, Madrid). Sin embargo, en la mayoría de los casos, no se puede decir que esta división obedezca a unidades lógicas. Incluso el concepto de Barrio es, al igual que el de la Ciudad y lo Urbano, muy utilizado, pero muy impreciso. Los habitantes de cada ciudad emplean con profusión el término, pero sus límites y concreción es dispar, por un lado la correspondiente a la división electoral o censal, por otro, a la estadística, en otro caso la registral o la que se efectúa en el ámbito de los servicios sociales para la atención de las unidades de trabajo social, la catastral, la urbanística o, en fin, la eclesial.

\footnotetext{
${ }^{7}$ En el mismo sentido al Reglamento de Población y Demarcación Territorial de las Entidades Locales aprobado por Real Decreto 169/1986, de 11 de julio.

${ }^{8}$ Se trata de la la Resolución de 9 de abril de 1997 de la Subsecretaría (Presidencia) por la que se dispone la publicación de la Resolución de 1 de abril, de la Presidenta del Instituto Nacional de Estadística y del Director General de Cooperación Territorial (BOE número 87, de 11 de abril de 1997).
} 
Como se expuso en el trabajo sobre "Las divisiones administrativas en las ciudades españolas, problemas que plantea su heterogeneidad, necesidad de un replanteamiento" ( $\mathrm{M}^{\mathrm{a}}$ José Aguilera Arilla y $\mathrm{M}^{\mathrm{a}}$ Pilar González YAnci, Espacio, Tiempo y Forma, Serier VI, Geografía, 1991): «Establecer en las ciudades unas divisiones de tamaño medio, que englobaran las secciones censales con fines electorales, pero en las que se consideraran criterios diversos y factores influyentes, buscando las áreas naturales de Zorbaugh, o algo similar ¿no ayudaría a mejor planificar y, en definitiva, a mejor administrar?»

En conclusión aunque debido a su sacralidad se deba mantener el mapa municipal actual -y también la, en general, extraña división en distritos y secciones de cada término municipal- no vemos por qué no se puede convertir la mayoría de los Municipios o bien en Entidades Locales menores, o en distritos pertenecientes a una determinada Ciudad ${ }^{9}$.

Aunque no se refiera específicamente a esta medida, Octavio Salazar Benítez en su Sistema de gobierno municipal [7] apunta la siguiente tendencia: Las ciudades pueden ser el espacio "policéntrico» de una nueva forma de gobernabilidad, hecha sobre la confluencia de múltiples procesos y actores, tanto públicos como privados. La suma del principio democrático y del de inmediatez hacen de los municipios el espacio más idóneo para desarrollar e incluso inventar, formas de organización capaces de profundizar en el sentido de comunidad y de permitir la consolidación de una ciudadanía «activa», alejada de comportamientos que favorecen las «grandes maquinarias» de las democracias «representativas» de los partidos.

Las reformas estatales de Régimen Local. El modelo de la Ley 7/1985, de 2 de abril, Reguladora de las Bases de Régimen Local no se ha visto afectado por las dos reformas de las que de forma sustancial ha sido objeto desde su promulgación.

La primera reforma operada por la Ley 11/1999, de 21 de abril fue consecuencia de lo que se ha venido a llamar el "Pacto local" y supuso un refuerzo en

\footnotetext{
${ }^{9}$ Una buena síntesis de los criterios de delimitación de ciudades se encuentra en el trabajo presentado por J. Roc Caldera al Primer congreso internacional de Ecología y Ciudad: La delimitación de la ciudad ¿una cuestión imposible? y también el artículo de Oriol Nello Los confines de la ciudad sin confines. Estructura urbana y límites administrativos en la ciudad difusa.
} 
la posición de los Alcaldes frente al Pleno reduciendo éste órgano a las funciones de aprobación de normas y del presupuesto local y de control de la acción de gobierno y administración, equilibrándose con una regulación más restrictiva de la legislación electoral de la moción de censura y la introducción de la cuestión de confianza, lo que supuso una parlamentarización del gobierno local; junto a ello se produjo la modificación de la Ley reguladora del Tribunal Constitucional para introducir el proceso denominado "Conflicto en defensa de la autonomía local".

La segunda reforma, fruto de la decepción que supuso el desarrollo del Pacto local en el ámbito local y en base a la demanda de la llamada "Segunda descentralización" fue operada por la Ley 57/2003, de 16 de diciembre, e introduce básicamente una serie de medidas en el régimen específico para los Municipios de gran población, un nuevo régimen de grandes ciudades, a las que pretende modernizar, así como una renovación del régimen del ejercicio de la potestad sancionadora. También supuso una reforma en materia de gestión de servicios públicos adecuando la tipología de los entes instrumentales a la Ley de Organización, Funcionamiento y Régimen Jurídico del Estado, las formas de gestión indirecta a la legislación contractual adicionándose distintos preceptos sobre entidades instrumentales sociedades mercantiles, entidades públicas empresariales y organismos autónomos locales.

Pese a la pretensión de enfatizar el contenido político de la autonomía local, lo cierto es que los controles políticos que habían sido previamente introducidos resultan inoperantes en el control de la gestión administrativa que es donde se desarrolla principalmente la actividad de gestión local. Por ello con esta última reforma se produce un agotamiento del modelo presidido [3], a pesar de la misma, por la Ley de Bases de Régimen Local (LBRL) y por planteada la necesidad de renovación precisamente por las deficiencias de la solución reformadora, sobre cuyo rediseño el Parejo Alfonso ha elaborado algunas pro$\operatorname{puestas}^{10}$.

${ }^{10}$ a) Sustentarse en la reafirmación de la posición constitucional propia de la instancia local en tanto que parte integrante, a mismo título que las demás instancias, de la organización territorial del Estado como un todo definida por el artículo 137 CE. Posición constitucional de la que partió correctamente la LrBRL y de la que deriva tanto la garantía de las correspondientes instituciones locales, como la condición de principio constitucional de distribución territorial del poder de la autonomía local garantizada (principio, que es así parte del entero sistema constitucional de distribución territorial del poder constituido). Y posición constitucional perfectamente compatible, en el Estado definido por la Constitución, con el reparto, diverso, entre las instan- 
En estos momentos la reforma del régimen local contemplada tanto en la propia Exposición de Motivos de la Ley 57/2003 como en los programas electorales de las grandes fuerzas políticas que concurrieron a las anteriores elecciones generales consistente en una nueva Ley de Bases del Régimen local, cuyo antecedente se encuentra en la elaboración del Libro Blanco [18] -también elaborado en el ámbito de Andalucía [19] - y el posterior borrador de anteproyecto de Ley de Gobierno Local - con sus directrices de renunciar a la tipificación de las entidades locales, el reforzamiento competencial de los municipios y el establecimiento de un verdadero sistema de gobierno local- se encuentra en una indefinida situación de espera.

cias territoriales superiores (el Estado en sentido estricto y las Comunidades Autónomas) de la disposición sobre el «marco legal» heterónomo definitorio de la instancia local. Pues este reparto diverso es consustancial al modelo específico de Estado constituido en 1978. La instancia local aquí aludida se entiende dotada de específica lógica interna (acorde con sus características y distinta a la de las instancias superiores) e integrada, salvo la improbable acometida de la reforma del actual mapa municipal, conjuntamente por el Municipio y la agrupación provincial de Municipios o equivalente autonómico de la misma, en el territorio continental, y la Isla en el territorio insular y dotada de lógica asimismo propia. Esta composición es asimismo específica, en tanto que centrada la agrupación municipal, de segundo grado, en la cobertura de la insuficiencia municipal para desarrollar adecuadamente sus propias funciones. Lo que quiere decir que dicha agrupación no es sino continuación, por otros medios institucionales, de la gestión de los mismos intereses municipales.

b) Efectuar una definición del régimen local básico manteniendo las líneas maestras del planteamiento adoptado por el legislador en 1985, pero i) ciñendo más aún aquel régimen a lo verdaderamente esencial y lo común estrictamente indispensable; ii) confirmandola identificación del núcleo de tal régimen con el sistema de gobierno y administración para la gestión de los intereses de las correspondientes colectividades locales; y iii) recuperando con todo vigor la garantía a favor de la potestad local de autoorganización y frente al legislador autonómico del entero espacio inscrito dentro de los límites resultantes del sistema básico de gobierno y administración; garantía expresiva así de un mínimo común coherente con la condición de núcleo duro de la autonomía local de la referida potestad de autoorganización y, al mismo tiempo, condición de la necesaria diversidad del régimen local y presupuesto de la plena efectividad de la autonomía local.

c) Establecer, sin perjuicio del obligado mantenimiento del sistema propio del Concejo abierto y asumiendo la aportación efectuada por las reformas de 1999 y 2003, un único sistema representativo de gobierno y administración local que, basado en su atribución al Alcalde y los Concejales, posibilite su plena «parlamentarización» en los términos autorizados por la Carta Europea de Autonomía Local y en función de las características de la colectividad local de que en cada caso se trate. Y esto último, con entera independencia de los regímenes especiales de que puedan disfrutar desde luego los Municipios de Barcelona y Madrid.

d) Entrega de la determinación del contenido competencial del Municipio (y, por reflejo, de la agrupación legal de éstos) a la instancia superior que tiene disposición legislativa sobre las materias en que se hacen presentes de ordinario los intereses de las colectividades locales, es decir, 


\subsection{La superación de la garantía institucional de la autonomía local}

El contenido concreto del término o concepto jurídico de autonomía constitucionalmente garantizada viene determinado en sus propios términos por el Tribunal Constitucional en el importante Fundamento jurídico 8 de la Sentencia $240 / 2006^{11}$. Sin embargo la posición mayoritaria es cuestionada en

a las Comunidades, incluso para la garantía del correspondiente espacio competencial en sede del Estatuto de Autonomía; todo ello desde la acotación básica de un núcleo mínimo de responsabilidades-competencias por relación a los asuntos más directamente vinculados a la convivencia sobre el territorio y constitutivos, por ello, del acervo tradicional de la gestión municipal.

${ }^{11}$ «Para determinar el contenido y la extensión de la autonomía local constitucionalmente garantizada, objeto de protección en este proceso (art. 75.bis.1 LOTC), debe partirse de nuestra reiterada doctrina según la cual la autonomía local reconocida en los arts. 137 y140 de la Constitución: se configura como una garantía institucional con un contenido mínimo que el legislador debe respetar y que se concreta, básicamente, en el "derecho de la comunidad local a participar a través de órganos propios en el gobierno y administración de cuantos asuntos le atañen, graduándose la intensidad de esta participación en función de la relación existente entre los intereses locales y supralocales dentro de tales asuntos o materias. Para el ejercicio de esa participación en el gobierno y administración en cuanto les atañe, los órganos representativos de la comunidad local han de estar dotados de las potestades sin las que ninguna actuación autonómica es posible" (STC 32/198), FJ 4)» (STC 40/1998, de 19 de febrero (FJ 39). Tal como declaramos en la STC 159/2001, de 5 de julio, FJ 5, se trata de una noción muy similar a laque luego fue acogida por la Carta Europea de la Autonomía Local de 1985 (ratificada por España en 1988), cuyo art. 3 («Concepto de la autonomía local») establece que por autonomía local se entiende el derecho y la capacidad efectiva de las entidades locales de ordenar y gestionar una parte importante de los asuntos públicos, en el marco de la ley, bajo su propia responsabilidad yen beneficio de sus habitantes.

En segundo lugar la referida doctrina no es trasladable a este proceso porque, a pesar de reconocer puntualmente «la singular y específica naturaleza y posición de [la Ley de las bases del régimen local] en el Ordenamiento jurídico» (STC 259/1988, de 22 de diciembre, FJ 2), de la jurisprudencia examinada no se concluye que la Ley reguladora de las bases del régimen local constituya siempre canon de validez de la ley, estatal o autonómica, a la hora de enjuiciar normas que desarrollen aspectos concretos de la autonomía local. De la ley estatal no lo constituye porque la Ley de las bases del régimen local, más allá de la referida naturaleza singular, y de su carácter básico ex art. 149.1.18 CE, no ocupa en nuestro Ordenamiento una posición distinta a las demás leyes ordinarias del Estado, que pueden por tanto establecer disposiciones contrarias a la Ley de las bases del régimen local, las cuales deberán ser consideradas modificaciones legislativas pero no leyes inconstitucionales. De la ley autonómica sólo podría ser canon de validez la Ley de las bases del régimen local en aquellos aspectos enraizables directamente en los arts. 137, 140 y 141 CE. En efecto, tal como declaró la STG 159/2001, de 5 de julio, Sólo aquellos extremos de la LBRL que puedan ser ca- 
el Voto particular formulado por el Magistrado don Jorge Rodríguez-Zapata Pérez a la Sentencia de 20 de julio de $2006^{12}$.Conviene resaltar la posición del Magistrado Rodríguez-Zapata Pérez quien se ha mostrado crítico con la posición mayoritaria de la Sala en los procedimientos en materia de conflicto de competencias no sólo a través del Voto particular reseñado a la Sentencia de 20 de julio de 2006 sino, también, en la Sentencia 47/2008. de 11 de marzo de 2008 promovido por el Ayuntamiento de Torrent y otros en relación con el artículo 2 y la disposición transitoria de la Ley de la Generalitat Valenciana 8/1999, de 3 de diciembre por la que se suprime el Área Metropolitana de l'Horta, en el que concluye de forma categórica que «Por todo lo expuesto, creo que resulta decepcionante que uno de los escasos conflictos en defensa de

balmente enraizados de forma directa en los arts. 137, 140 y 141 CE, de cuyo contenido no representen más que exteriorizaciones o manifestaciones, forman parte del contenido de la autonomía local constitucionalmente garantizada, mientras que los que se refieran a aspectos secundarios o no expresivos de ese núcleo esencial en el que consiste la garantía institucional, que son mayoría en el seno de la LBRL y que se incardinan, desde el punto de vista competencial, en el art. 149.1.18 CE, tienen una distinta naturaleza desde el punto de vista constitucional y ordinamental (FJ 4).

Las anteriores consideraciones permiten concluir que el canon que este Tribunal deberá aplicar para resolver los conflictos en defensa de la autonomía local promovidos frente a leyes estatales se ciñe a los preceptos constitucionales (arts. 137, 140 y $141 \mathrm{CE}$ ) que establecen ese contenido mínimo que protege la garantía institucional y que hemos considerado definitorios de los elementos esenciales o del núcleo primario del autogobierno de los entes locales territoriales. También el legislador básico estatal ha de respetar la garantía institucional de la autonomía local (STC 109/1998, de 21 de mayo, FJ 2), puesto que los destinatarios del art. 137 CE son todos los poderes públicos, y más concretamente todos los legisladores (STC 11/1999, de 11 de febrero (FJ 2). Pero la legislación básica sobre régimen local no se integra en el bloque de la constitucionalidad ni constituye canon de validez respecto de otras leyes estatales. Tal como sostiene el Abogado del Estado no puede pretenderse de este Tribunal que enjuicie una norma estatal utilizando como parámetro otra norma estatal (configuradora de la autonomía local constitucionalmente garantizada) pues, lógicamente, si no se ha vulnerado la Constitución debe interpretarse como una nueva opción del legislador. Por otra parte tampoco en este proceso puede discutirse el carácter básico de la norma estatal, ya que ésta es una cuestión que afecta al régimen de distribución de competencias entre el Estado y las Comunidades Autónomas que, consiguientemente, no puede ser suscitada en este proceso constitucional por las entidades locales legitimadas para promoverlo.»

$12 « 5$. No puedo dejar de señalar que una limitación de los conflictos en defensa de la autonomía local deriva también, en mi opinión, de la muy escueta función constitucional que atribuye el FJ 8 de la Sentencia mayoritaria a la Ley 7/1985, de 2 de abril, reguladora de las bases de régimen local. Creo (por todas, STC 27/1987, de 27 de febrero, FJ 4) que la LBRL sí sirve de parámetro para enjuiciar la constitucionalidad de las leyes y normas de las Comunidades Autónomas.» 
la autonomía local que ha logrado superar las indudables dificultades que su planteamiento encuentra en nuestra Ley Orgánica, no alcance a ser resuelto, pese a haber sido planteado hace más de siete años, por razón tan discutible como la apreciada en la Sentencia que declara su pérdida de objeto.»

Esta decepción se puede constatar consultando los resultados de los conflictos en defensa de la autonomía local, a los que luego nos vamos a referir, que se han suscitado ante el Tribunal constitucional: de los once procedimientos abiertos, se han inadmitido a trámite seis (Autos números 419/2003, de 16 de diciembre de 2003, Auto número 360/2005, de 11 de octubre de 2005, Auto número $361 / 2005$, de 11 de octubre de 2005, Auto número 362/2005, de 11 de octubre de 2005, Auto número 363/2005, de 11 de octubre de 2005, Auto número 322/2007, de 3 de julio de 2007); se han declarado extinguidos por falta de objeto tres (Auto 513/2004, de 14 de diciembre, Auto 326/2007, de 12 de julio, y Sentencia 47/2008, de 11 de marzo); y, finalmente, se ha resuelto sólo uno, desestimatorio del conflicto en defensa de la autonomía (sentencia 240/2006, de 20 de julio).

Pero es que, además, la posición representada en la Sentencia de 20 de julio de 2006 parece insistir en una construcción dogmática del principio de autonomía local, el de garantía institucional, que aunque se ha revelado útil para que el legislador no vacíe completamente de contenido a un nivel constitucionalmente garantizado, no delimita el contenido esencial que protege velando únicamente, de forma defensiva, por la no vulneración de la institución, la cual se aleja de la tendencia doctrinal representada por la teoría de la garantía constitucional, que se refiere a una autonomía local en sentido positivo conforme a un análisis hermenéutico de la Constitución, en virtud del cual la norma fundamental no implica el reducto indisponible para el legislador ordinario, sino un auténtico mandato constitucional, tanto de suficiencia como de optimización del principio de autonomía local [26]. De forma que la regulación constitucional no se limite a los artículos 137, 140, 141 y 142 de la Constitución sino a toda la norma fundamental, y así, con los principios definidores del Estado y los valores superiores del ordenamiento jurídico (artículos 1 y 9 de la Constitución) y los articuladores de la Administración Pública como la descentralización (artículo 130.1) de acuerdo con el derecho fundamental consagrado en el artículo 23.1 y de los mandatos de los poderes públicos expresados en el artículo 9.2, bajo el control de los Tribunales en los términos del artículo 106.1.

El conflicto en defensa de la autonomía local. Tal y como se recoge en la STC 240/2006 de 20 de julio, el conflicto en defensa de la autonomía local: «constituye una vía para la defensa específica de la autonomía local an- 
te el Tribunal Constitucional,tal como reza la citada exposición de motivos de la Ley Orgánica 7/1999. Dicha especificidad se manifiesta en que el conflicto sólo puede ser promovido frente a normas legales con base en un único motivo de inconstitucionalidad, la lesión de la autonomía local constitucionalmente garantizada;en consecuencia no podrán alegarse en él otros motivos fundados en la infracción de preceptos constitucionales que no guarden una relación directa con la autonomía que la Constitución garantiza a los entes locales. La legitimación activa para plantear el conflicto en defensa de la autonomía local se reserva específicamente a determinados entes locales. La exposición de motivos de la Ley Orgánica 7/1999 expresa la necesidad de limitar el ámbito de los sujetos legitimados,puesto que se trata de garantizar los intereses de los entes locales afectados ponderando su entidad, de modo que los mismos sean suficientemente representativos y que no se refieran a los propios de los entes locales aisladamente considerados.De ahí que la Ley Orgánica 7/1999, al especificar los sujetos que pueden plantear el conflicto en defensa de la autonomía local, contemple únicamente a los municipios y provincias (art. 59.2 LOTC), además de a los enumerados en las disposiciones adicionales tercera y cuarta que incorporó a la Ley Orgánica de este Tribunal. Y de ahí que el art. 75.ter LOTC (igualmente introducido en este cuerpo legal por la Ley Orgánica 7/1999) establezca unas estrictas reglas para la legitimatio ad causam que serán examinadas seguidamente».

Por su parte la STG 47/2008, de 11 de marzo, aunque declara extinguido por perdida de objeto el conflicto en defensa de la autonomía local planteado en relación con le artículo 2 y la disposición transitoria de la Ley de la Generalitat Valenciana 8/1999, de 3 de diciembre, por la que se suprime el área Metropolitana de l'Horta, con el voto particular arriba reseñado, reseñando la Exposición de Motivos de la Ley Orgánica 7/1999 especifica que lo que se trata en este proceso es en definitiva de: «garantizar los intereses de los entes locales afectados ponderando su entidad, de modo que los mismos sean suficientemente representativos y que no e refieran a los propios de los entes locales aisladamente considerados.»

Un aspecto destacado en el voto particular, es la paradójica situación que recuerda incidentalmente como el Tribunal Constitucional ha llegado a considerar como objeto de control de constitucionalidad en la STC 126/1997, nada menos que la Partida 2.15.2 del Rey Sabio, cuyo contenido se veía resucitado por diversas normas de remisión ${ }^{13}$.

13 «... . ...Debo recordar que, como hemos explicado en múltiples ocasiones, la apreciación de la pérdida de objeto de un proceso dependerá del tipo del proceso constitucional de que se 
A la vista de todo lo expuesto podemos decir que la configuración del conflicto de defensa de la autonomía local está cuestionada desde todos los puntos de vista [45] al punto de estar planteada, desde el año 2005, el debate político sobre la necesidad de modificar la Ley Orgánica del Tribunal Constitucional, entre otros, en este aspecto, no sólo por las importantes dificultades técnicas y prácticas de esta figura, en especial en cuanto a la legitimación activa o por la necesidad de acometer una duplicidad de procedimientos para que se produzca de forma definitiva inconstitucionalidad de la norma legal, tal y como señala Vilalta Reixach. ${ }^{14}$

\subsection{La participación de los entes locales en la elaboración de las normas}

La marginación de los entes locales en el ámbito de la decisión política del Estado es tal, que el único vestigio de representación con el que cuenta en el Poder legislativo es la Comisión de Entidades Locales del Senado, formada por Senadores en número proporcional a la representación que cuenta cada grupo, sin que la actividad que presta sea relevante [45].

La participación de los entes locales queda reducida en el ámbito legislativo a la que corresponde de forma puntual y tímida a la comparecencia de

trate y de la incidencia real que sobre el mismo tenga la derogación, sustitución o modificación de la norma, no pudiendo resolverse apriorísticamente en función de criterios abstractos o genéricos. Y ello porque lo relevante no es tanto la derogación o modificación de la concreta norma impugnada cuanto determinar si con esa alteración ha cesado o no la controversia que se planteaba, pues, en ocasiones, aun habiendo sido expulsada la norma del ordenamiento jurídico se mantiene viva la necesidad de dar respuesta al problema constitucional planteado. En concreto, cuando nos encontramos en presencia de una controversia competencial, la modificación de las disposiciones cuya adopción dio lugar al litigio no tiene por qué enervar automáticamente la disputa surgida, sobre todo si esa normativa en relación con la cual se trabó el conflicto es sustituida por otra posterior que deja intacto el problema competencial planteado (por todas, la STC 137/2003, de 3 de julio, FJ 2).»

14 «Al mismo tiempo, el conflicto en defensa de la autonomía local se configura esencialmente como un mecanismo de carácter negativo y a posteriori, que permite reaccionar eficazmente frente a leyes que supongan un desapoderamiento ilegítimo de una competencia local ya asignada o que se interfiera en el ejercicio de éstas, pero de muy difícil plasmación en aquellos casos en que la cuestión a analizar no es la vulneración de una determinada competencia ya atribuida a los entes locales, sino precisamente la falta de reconocimiento de ésta. De manera que su operatividad es mucho menor cuando lo que se persigue es inculcar positivamente al legislador, reclamándole la asignación de específicas competencias públicas.» 
cualquier autoridad o experto que sea recabada para informar durante la tramitación de cualquier proyecto.

Por otro lado, y en el ámbito de la Administración General del Estado, la participación de las entidades locales está prevista en el artículo 117 de la Ley 7/1985, en el ámbito de la Comisión Nacional de Administración Local si bien limitándose a determinadas materias ${ }^{15}$.

Por otro lado, prácticamente desde la supresión del Instituto de Estudios de Administración Local y su absorción por el Instituto Nacional de Administraciones Públicas ${ }^{16}$ la única información relevante en materia de régimen local es la que dispone el Ministerio de Economía y Hacienda.

¿Qué ha sido del Observatorio Urbano señalado en la Disposición Adicional Novena de la Ley $7 / 1985$, de 2 de abril (Añadida por art. 1.3 de Ley $57 / 2003$, de 16 diciembre) establecido con la finalidad de conocer y analizar la evolución de la calidad de vida en los municipios regulados en el título $\mathrm{X}$ de esta Ley, a través del seguimiento de los indicadores que se determinen reglamentariamente, ¿se trata sólo de una herramienta informática al tipo del proyecto europeo Urban Audit o se ha convertido en otro observatorio, el de grandes ciudades, dependientes de la Conferencia de Grandes Ciudades que se pretendía constituir tras las elecciones locales de 2007.

La articulación de la participación de los Entes Locales queda reducido pues a la interlocución de los diferentes agentes con la Federación española de Municipios y Provincias, una mera Asociación (o club) constituido al amparo de la Disposición Adicional Quinta de la Ley 7/1985 de 2 de abril, declarada de utilidad pública mediante Acuerdo de Consejo de Ministros de 26 de junio de 1985, integrada por los Municipios, Provincias y otros Entes Locales que voluntariamente lo decidan.

${ }^{15}$ El Pleno deberá informar en los siguientes asuntos: a) Normativa básica de régimen local, b) Haciendas Locales y, c) Leyes Orgánicas que afecten a la Administración Local.

${ }^{16}$ La refundición del Instituto de Estudios de Administración Local con el Instituto Nacional de Administración Pública en un solo organismo autónomo con la denominación de éste último se produjo por el Real Decreto 1437/1987 de 25 de noviembre. 
Y, en el ámbito de las Comisiones en lo casos siguientes: A) Emitir informe en los siguientes supuestos: a) Anteproyectos de ley y proyectos de disposiciones administrativas de competencia del Estado en las materias que afecten a la Administración local, tales como las referentes a su régimen organizativo y de funcionamiento; régimen sustantivo de sus funciones y servicios -incluidas la atribución o supresión de competencias-; régimen estatutario de sus funcionarios; procedimiento administrativo, contratos, concesiones y demás formas de prestación de los servicios públicos; expropiación y responsabilidad patrimonial; régimen de sus bienes y haciendas locales. b) Criterios para las autorizaciones de operaciones de endeudamiento de las Corporaciones locales. c) Previamente y en los supuestos en que el Consejo de Ministros acuerde la aplicación de lo dispuesto en el artículo 61RCL $1985 \backslash 799$ de la presente Ley.

B) Efectuar propuestas y sugerencias al Gobierno en materia de Administración local y, en especial, sobre: a) Atribución y delegación de competencias en favor de las Entidades locales. b) Distribución de las subvenciones, créditos y transferencias del Estado a la Administración local. c) Participación de las Haciendas locales en los tributos del Estado. d) Previsiones de los Presupuestos Generales del Estado que afecten a las entidades locales.

\section{EL RÉGIMEN LOGAL Y LOS ESTATUTOS DE AUTONOMÍA DE SEGUNDA GENERACIÓN}

\subsection{El nuevo paradigma}

La omisión, o renuncia, de la Ley 57/2003, para resolver los problemas de orden financiero y competencial de los entes locales ha dado lugar a que en los procesos de reforma estatutaria se proceda a una "interiorización" del régimen local en el ámbito competencial e institucional de las Comunidades Autónomas [36] en lo que se denomina una subconstitucionalización territorial.Ésta subsconstitucionalización se está produciendo de forma inmediata en el ámbito de las Comunidades Autónomas que cuentan con Estatutos de autonomía de «segunda generación» y que por tanto no alcanza aún a las denominadas Comunidades autónomas uniprovinciales ni, desde luego, a las Comunidades «uni-municipales» de Ceuta y Melilla cuyo nivel mínimo de autonomía local vendría dado de acuerdo con la formulación planteada dado por las bases de régimen jurídico de las Administraciones públicas previsto en el artículo 149.1.18 de la Constitución española. 
Los nuevos Estatutos de Autonomía - producto para algunos de una re-interpretación o mutación constitucional y, para otros, de la aplicación del Uso Alternativo del Derecho en el ámbito constitucional- en la mayoría de casos han asumido la propuesta doctrinal en parte recogida en el Informe de la Comisión de expertos que dictamina las alegaciones al Libro Blanco [27] por la que se propone una atribución directa de competencias a los entes locales superando la técnica de la remisión a la legislación sectorial, a través de la inclusión en los Estatutos de Autonomía de regulaciones sobre el régimen competencial y financiero de las Entidades Locales. Conforme a esta doctrina, que es asumida por el Informe emitido en 2003 sobre la Reforma del Estatuto de Cataluña por Instituto de Estudios autonómicos, los nuevos Estatutos de Autonomía o de segunda generación como normas de cabecera del ordenamiento de la Comunidad, constituyen el vehículo normativo más adecuado para garantizar la autonomía local debido a su rango formal de Ley Orgánica frente a las limitaciones de las bases normativas estatales para vincular una política legislativa de la Comunidad Autónoma.

El legislador estatal básico tendría entonces competencia para establecer una regulación mínima y homogénea del sistema de competencias local y de las distintas materias que figuran en las STC 214/89 pudiendo actuar, con mayor o menor extensión, en materia de entes locales necesarios y en la configuración de sus órganos de gobierno obligatorios [27], limitándose a informar los principios para obtener una regulación armónica pero sin desautorizar aquellas competencias o atribuciones que se hayan asignado directamente a las Comunidades Autónomas en su Estatuto. En fin, se puede decir que la competencia normativa del Estado sobre régimen local se limita a lo establecido en el artículo 149.1.18 de la Constitución, es decir, el establecimiento de las bases de régimen jurídico de las Administraciones públicas.

Sobre esta base se ha de indicar que compartimos la posición expuesta por Luis Ortega [36] en el sentido de que no existían razones de peso, sobre la base de la experiencia acumulada, para promover la interiorización y el cambio de modelo que se ha producido en esta materia ya que lo que tendría sentido es introducir, en una futura reforma constitucional, principios de ordenación y garantía del régimen local que permitan una activación más eficaz de los instrumentos de defensa de la autonomía local. Con otros motivos también compartimos la posición de José María Rodríguez de Santiago expuesta en el Prólogo al tratado del profesor Francisco Velasco Caballero sobre el Sistema de Fuentes en el Derecho Local [14] cuya posición es completamente inversa a la recogida en 1981 en el Informe de la Comisión de expertos sobre Autonomías resaltada [2] por la doctrina administra- 
tiva de entonces ${ }^{17}$. En el mismo sentido recientemente se ha pronunciado De la Quadra-Salcedo [20] quien trata de matizar la posición planteada por Velasco [14] en el siguiente sentido:

En todo caso los principios de articulación de las normas de distintos sistemas no pueden alterarse sobre la base del principio de jerarquía. Es el de competencia el que debe regir su relación. No vale por tanto invocar una supuesta mayor jerarquía del Estatuto para alterar los equilibrios hasta ahora conseguidos y, sobre todo, no puede hacerse una interpretación que haga inútil la reserva de competencias exclusivas al Estado del 149.1 de la que no puede siponerse sin modificar previamente la Constitución.

$\mathrm{Al}$ objeto de comprender lo que está pasando en estos momentos en el régimen local español con los nuevos estatutos de Autonomía nos vamos a fijar en el desarrollo estatutario correspondiente a Andalucía que sigue la senda, agrandes rasgos, del nuevo Estatuto catalán.

\subsection{El Régimen Local en el Estatuto de Andalucía}

Garantías de la Autonomía en el Estatuto para Andalucía. El artículo 108 del Estatuto de Autonomía de Andalucía (EAA) prevé la existencia

17 «Partiendo de estos presupuestos y superando las dificultades interpretativas del artículo 149.3, provocada por la definición estatuaria como exclusivas de competencias sobre materias enumeradas en el número 1 del mismo precepto constitucional, la Comisión sienta, en síntesis y a la hora de concretar el posible contenido de una Ley Orgánica de ordenación del proceso autonómico. Las siguientes conclusiones:

El sentido evidente del artículo 149.3 es que, cuando el Estado dispone de competencias exclusivas sobre una materia o su competencia legislativa es concurrente con la autonomía, las normas estatales priman sobre las emanadas por las Comunidades Autónomas.

El ámbito de aplicación de esa primacía del Derecho estatal debe entenderse que cubre -por la ubicación sistemática del precepto, la función ordenadora que pretende cumplir y la realidad a la que sirve- cuando menos y desde luego la materias del artículo 149.1, porque sobre las mismas recaen necesariamente competencias estatales, bien exclusivas, bien concurrentes.

El precepto no pone en cuestión la existencia de un ordenamiento territorial propio de cada Comunidad, pero sí que ese ordenamiento pueda entrar en colisión (e imponerse) con el ordenamiento del Estado cuando ambos regulen concurrentemente una misma materia.

La resolución de ese conflicto en favor del Derecho estatal es una exigencia del a coherencia del régimen jurídico de la materia de que se trate y un requisito de la unidad superior de ambos ordenamientos - estatal y autonómico- en el ordenamiento constitucional y general, unidad proclamada en el artículo 1 del texto constitucional.» 
de una serie de leyes que precisan para su aprobación la mayoría absoluta, lo que se ha denominado leyes institucionales según expresión de J.M. Porras Ramírez [15], una suerte de leyes orgánicas autonómicas. Entre éstas se encuentran las leyes que afectan a la organización territorial. La Ley de régimen local prevista en el artículo 98 tiene esta naturaleza al estar incluida en el Título III correspondiente a la Organización territorial de la Comunidad Autónoma y por tanto su aprobación precisará mayoría absoluta.

El artículo 89.2 del EAA garantiza la autonomía local con el alcance concreto establecido en la Carta Europea de la Autonomía Local, por lo que desde ahora tiene carácter estatutario este tratado internacional en Andalucía.

Junto a ello el nuevo Estatuto contiene reservas autonómicas para regular aspectos de régimen local como es el caso de los artículos 89.1 para la creación de las nuevas entidades territoriales, el artículo 93 en materia de transferencias y delegaciones, el artículo 94 en cuanto a funciones de las áreas metropolitanas, mancomunidades, consorcios y otras agrupaciones de municipios, el artículo 96.4 en relación con la reserva de Ley por mayoría absoluta la coordinación provincial, el artículo 97.2 sobre creación de comarcas así como la legislativa del artículo 98.

El EAA garantiza sólo para los municipios andaluces (por lo que se excluye a las Diputaciones Provinciales) "la plena capacidad de autoorganización dentro del marco de las disposiciones generales establecidas por Ley en materia de organización y funcionamiento municipal" (artículo 91.3 EAA), así como un "núcleo competencial propio que será ejercido con plena autonomía con sujeción sólo a los controles de constitucionalidad y legalidad" que se plasma en un listado en el artículo 92.2 EAA en los que se recogen las materias donde debe haber competencias propias de los ayuntamientos ${ }^{18}$. El apartado final o

\footnotetext{
${ }^{18}$ Conforme al artículo 92.2 del Estatuto los Ayuntamientos tienen competencias propias sobre las siguientes materias, en los términos que determinen las leyes: a) Ordenación, gestión, ejecución y disciplina urbanística. b) Planificación, programación y gestión de viviendas y participación en la planificación de la vivienda de protección oficial. c) Gestión de los servicios sociales comunitarios. d) Ordenación y prestación de los siguientes servicios básicos: abastecimiento de agua y tratamiento de aguas residuales; alumbrado público; recogida y tratamiento de residuos; limpieza viaria; prevención y extinción de incendios y transporte público de viajeros. e) Conservación de vías públicas urbanas y rurales. f) Ordenación de la movilidad y accesibilidad de personas y vehículos en las vías urbanas. g) Cooperación con otras Administraciones públicas para la promoción, defensa y protección del patrimonio histórico y artístico andaluz. h) Coope-
} 
cláusula residual establecido en la letra ñ), deberá entenderse con el alcance recogido en el artículo 108 del EAA en el sentido de que cualquier atribución de competencias, o modificación de las existentes, precisará del trámite parlamentario de mayoría absoluta exigido para la aprobación de la Ley de Régimen Local sin que ello suponga una cosificación del mismo.

Parece com si el estudio efectuado por el profesor Velasco [14] sobre el sistema de fuentes del Derecho Local ${ }^{19}$ haya sido asumido en los sistemas instaurados por los nuevos Estatutos de Autonomía cuyo objeto ha de ser la elevación de los «estándares» mínimos de autonomía local a la que también aspiran los documentos de la FAMP [22].

En desarrollo del Estatuto se han aprobado dos leyes autonómicas y se encuentra en trámite, en estos momentos el Anteproyecto de Ley de Autonomía Local de Andalucía que brevemente pasamos a analizar.

ración con otras Administraciones públicas para la promoción, defensa y protección del medio ambiente y de la salud pública. i) La regulación de las condiciones de seguridad en las actividades organizadas en espacios públicos y en los lugares de concurrencia pública. j) Defensa de usuarios y consumidores. k) Promoción del turismo. 1) Promoción de la cultura, así como planificación y gestión de actividades culturales. m) Promoción del deporte y gestión de equipamientos deportivos de uso público. n) Cementerio y servicios funerarios. ñ) Las restantes materias que con este carácter sean establecidas por las leyes.

${ }^{19}$ «En lo que sigue voy a ejemplificar la función autonómica de elevación de los «estándares» mínimos de autonomía local con el sistema de competencias municipales establecido en la LBRL. En materia de competencias municipales existe un amplio margen para la elevación autonómica de los «estándares» básicos de autonomía local. Porque el estándar mínimo de autonomía competencial es relativamente bajo. Como es sabido, los arts. 2.1 y 25.2 LBRL encargan a la ley sectorial (estatal o autonómica) la atribución de concretas competencias en las materias que expresamente se relacionan. La mayoría de estas materias corresponde a las Comunidades Autónomas. Y por ello el encargo de la LBRL normalmente va dirigido al legislador autonómico. Aquí, por tanto, el margen de configuración de la autonomía local, por parte de la ley autonómica, es potencialmente muy amplio. Dado que el listado de materias del art. 25.2 LBRL es sólo un «estándar» mínimo de autonomía municipal, la ley autonómica puede (e incluso ponderadamente debe) atribuir competencias en otras materias de titularidad autonómica. Como ha dicho el Tribunal Superior de Justicia de la Comunidad Valenciana: «[La Comunidad] podría conferir competencias a los Municipios en esta materia [deporte] más allá del marco de la Ley 7/1985, con el fin de aproximar la gestión pública a los ciudadanos en la línea del art. 4.3 CE$\mathrm{AL} »$ 
El Gonsejo Andaluz de Concertación Local. La Comunidad Autónoma de Andalucía ha sido pionera en el desarrollo de las previsiones del nuevo Estatuto en materia de Régimen Local dando cumplimiento a la habilitación prevista en el artículo 95 que remite a una ley del Parlamento la creación, composición y funciones del nuevo órgano de relación entre la Junta de Andalucía y los Ayuntamientos andaluces. Mediante la Ley 20/2007, de 17 de diciembre, se crea y regula el Consejo Andaluz de Concertación Local como órgano para la relación, colaboración y coordinación entre las Administración de la Junta de Andalucía y las entidades locales andaluzas.

La configuración estatutaria del órgano de "concertación local", la opción por un modelo mixto o dualista, su ámbito funcional, el régimen jurídico de un órgano que sólo tiene atribuidas funciones asesoras o consultivas en sentido estricto, la tramitación parlamentaria de las disposiciones legislativas y de los planes que afecten de forma especial a las corporaciones locales, cuyos dictámenes no son vinculantes no ha estado exento de críticas [52] fundamentalmente derivada de la composición mixta del órgano dando más valor al voto de los representantes autonómicos que al de la representación local lo que hace que la ley se quede más "en el terreno de las medidas estéticas que en el de las soluciones útiles". Se ha evitado con ello contrapesar la dinámica centrífuga del sistema. Se trata en definitiva de un órgano de la propia Junta de Andalucía que se encuentra bajo su control político y sobre el cual ya se ha desvanecido cualquier ilusión de participación efectiva de las entidades locales [12]. De hecho desde la designación e integración de miembros poco más se conoce de la actividad realizada por este órgano que parece efectivamente un sucesor natural (sic Disposición Adicional $1^{a}$ ) de otros órganos consultivos locales que se han mostrado ineficaces hasta hoy como el Consejo Andaluz de Municipios y el Consejo Andaluz de Provincias.

Resulta inevitable señalar que esta posición de lo municipal se debe en gran parte a un disminuido peso constitucional de los municipios en términos estructurales, «pese a la evolución del papel que ha jugado desde 1978 el nivel local en la transformación territorial española», cuyo cambio tendría que sobreponerse a los intereses, fuerzas adquiridas e identidades que, en un cuarto de siglo, han cultivado las Comunidades Autónomas [48] lo que conlleva a nuestro juicio, un«encapsulamiento» o«empotramiento» de lo local en el nivel intermedio.

La Laula ha tratado de superar esta figura, sin eliminarla, integrándola en un denomanado Consejo Andaluz de Gobiernos Locales (artículo 57) como órgano de representación de los municipios y las provincias ante las instituciones 
de la Junta de Andalucía con la finalidad de garantizar el respeto a las competencias locales que une cinco cargos electos locales propuestos, en principio, de la FAMP.

Acceso de los municipios andaluces al régimen de gran población. $\mathrm{Al}$ amparo del artículo 60 del Estatuto de Autonomía se ha dictado la Ley 2/2008 de 10 de diciembre que regula el acceso de los municipios andaluces a la organización de los municipios de gran población conforme con la modificación efectuada en la Ley 7/1985, de 2 de abril, por la Ley 57/2003, de 16 de diciembre, y es de aplicación a los municipios andaluces que sean capitales de provincia o sedes de las instituciones autonómicas, así como a los municipios de más de 75.000 habitantes, que presenten circunstancias económicas, sociales, históricas o culturales especiales, de conformidad con lo previsto en el artículo 121.1.c) y d) de la Ley $7 / 1985$, de 2 de abril, reguladora de las Bases del Régimen Local, y soliciten al Parlamento de Andalucía su inclusión en el régimen de organización de los municipios de gran población. En este punto el legislador andaluz ha renunciado a cualquier tipo de innovación.

La Ley de Autonomía Local de Andalucía. Durante el mes de octubre de 2009 la Consejería de Gobernación de la Junta de Andalucía sometió a audiencia el Anteproyecto de Ley de Autonomía Local de Andalucía que ha sido finalmente aprobado por el Pleno del Parlamento en sesión celebrada los días 26 y 27 de mayo de 2010 y publicada en el BOJA núm. 122 de 23 de junio de 2010). Aunque es prematuro efectuar cualquier valoración crítica, dado que se trata de una Ley que entrará en vigor el próximo 24 de julio de 2010 el texto supone un acierto en la medida en que transcribe disposiciones de la Primera Parte de la Carta europea de la Autonomía Local, y, un fracaso, en lo que matiza, relativiza u omite del mismo Tratado.

Hay que destacar como aspectos positivos la regulación que se encuentra en el Título II de los Servicios y la iniciativa económica local conforme a la competencia exclusiva sobre modalidades de prestación de los servicios públicos locales que tiene atribuida la Comunidad Autónoma de Andalucía de acuerdo con el art. 60 1.c) Estatuto de Autonomía de Andalucía (EAA) y, en el plano negativo, la posición unilateral que la Junta de Andalucía se atribuye en sus relaciones con respecto a las entidades locales tal y como propone su Título IV matizada por la figura del Consejo Andaluz de Gobiernos Locales y sobre cuyos aspectos en materia de coordinación nos vamos a referir aparte.

En cuanto la enunciación de competencias es muy pormenorizada y pese a la apariencia autonomista, la Ley, como tampoco el Estatuto de Autonomía, 
supone una garantía adicional a las Corporaciones Locales al ser un desarrollo y reproducción de las contenidas en los artículos 25 y siguientes de la Ley $7 / 1985$.

Si se pretende que la autonomía local no quede degradada definitivamente en Andalucía, se deberá delimitar en la legislación sectorial cuál es el marco competencial propio de forma que no se desproteja y vacíe de contenido las competencias propias y exclusivas en principio atribuidas. Tal y como expone el artículo 4 de la Carta Europea de Autonomía Local: "Las competencias encomendadas a las Entidades locales deben ser normalmente plenas y completas. No pueden ser puestas en tela de juicio ni limitadas por otra autoridad central o regional, más que dentro del ámbito de la Ley". Pero, sobre todo, se deberá prohibir a la Administraciones estatal y autonómica que basen su relación con la Administración Local en la asignación de los recursos generales mediante la financiación afectada, a través de subvenciones finalistas, que está condicionando en los últimos tiempos, de una forma letal, su margen de autonomía.

La Coordinación autonómica en la LAULA. Resulta evidente que el artículo 58 de la Ley de Autonomía Local de Andalucía (LAULA) es una mera adaptación del actual artículo 59 de la Ley de Bases de Régimen Local (LBRL).

El precepto de la LAULA no supone por tanto ninguna innovación al ordenamiento jurídico actual, al contrario, sigue la posición conservadora con que ha sido interpretado el precepto estatal por el Tribunal Constitucional (TC) en la Sentencia número 214/1989.

No obstante hay que decir que el artículo 59 de la LBRL no prevé facultades coordinadoras con carácter general sino, tal y como se expreso el TC en la Sentencia reseñada:

«(.../...) En función del reparto de competencias en los diversos sectores de la acción pública en los que se ponga de manifiesto la necesidad de garantizar la coherencia de la actuación de las Administraciones Públicas, y siempre que, además tal como prevé el art. 10.2 de la L.R.B.R.L. «las actividades o los servicios locales transciendan el interés propio de las correspondientes Entidades (locales), incidan o condicionen relevantemente los de dichas Administraciones o sean concurrentes o complementarios de los de éstas». Quiere decirse, pues, que, en el art. 59.1 de la LBRL, al Estado no se le atribuye indebidamente competencia alguna que no le corresponda a fin de coordinar la actuación de las Entidades locales, produciéndose así un desapoderamiento correlativo de 
las Comunidades Autónomas. Antes bien, hay una expresa remisión a los diversos sectores materiales en los que venga a manifestarse la actuación administrativa que reclame esa coordinación, sin prejuzgar, por tanto, la titularidad misma de la competencia en cada caso».

Cuando el legislador autonómico se limita a transcribir un precepto estatal en la normativa propia del régimen local está renunciando a asumir la función de completar y reforzar la autonomía local en el marco de la comunidad.

Hemos discrepado de la transcripción de este precepto con anterioridad (en alegaciones formuladas por Colegio Oficial de Secretarios, Interventores y Tesoreros de Andalucía al Anteproyecto) e interesado su supresión sin más ya que, en estos términos, resulta innecesario. Se trata, en principio, de una mera posición formal: la simplicidad del sistema, no abigarrar aún más nuestro ordenamiento jurídico material.

Desaprovechar la elaboración de la Norma institucional para adaptar el sistema local constituye asumir un riesgo: el de la cosificación de un sistema administrativo. Por otro lado tampoco la doctrina del Tribunal Constitucional es invariable, no se puede predecir una relectura del precepto en el ámbito autonómico actual, como tampoco lo fue cuando analizó la remisión expresa que el artículo 118 de la Ley de Costas realizaba al artículo 59 de la LBRL mediante la STC 149/1991 de 4 de julio, al declararlo inconstitucional.

¿Hasta que punto el artículo 58 de la LAULA incumple igualmente la exigencia establecida en el apartado segundo del art. 59 de la LBRL al no precisar, con suficiente detalle, las condiciones y los límites de la coordinación, así como las modalidades de control que se reserven el Parlamento andaluz?

Sobre la base de la definición de la autonomía local que recoge el artículo 3 de la Carta europea de Autonomía local, las entidades locales están excluidas de la dependencia jerárquica y, sobre las mismas no cabe cualquier control de oportunidad política ya que responden directamente ante el cuerpo electoral en un ámbito territorial limitado.

El Tribunal Constitucional indicó en la STC 27/1987 que: "las técnicas de coordinación no pueden traducirse en la emanación de órdenes concretas que prefiguran exhaustivamente el contenido de la actividad del ente coordinando, agotando su ámbito propio de decisión autónomo: en cualquier caso, los medios y técnicas de coordinación deben respetar un margen de libre deci- 
sión o de discrecionalidad a favor de las administraciones sujetas a la misma, sin el cual no puede existir verdadera autonomía".

Por su parte el principio de autonomía está vinculado con el principio de corresponsabilidad fiscal entendido como visibilidad o perceptibilidad establecido por la Comisión Layfield que como ha señalado Ruiz Huerta en su trabajo "La articulación de la corresponsabilidad fiscal en el modelo autonómico español" (Financiación Autonómica y Corresponsabilidad Fiscal en España, Fundación BBV, Bilbao):

"dice el Green Paper que las autoridades públicas deben ser responsables ante su electorado de lo que gastan y de los ingresos que obtienen. Para estimular la eficiencia y evitar los comportamientos extravagantes de las autoridades locales sus electores deben conocer claramente las decisiones de gastos e ingresos que toman, así como los efectos de dichas decisiones sobre los niveles de impuestos locales que deben pagar. Para favorecer la responsabilidad, un tributo local debe ser claramente perceptible por los electores locales y contribuyentes, quienes deben conocer explícitamente qué volumen de impuestos están tributando, a qué institución o autoridad están pagando y cuáles son los servicios que dicha autoridad está suministrando. Por último, hasta donde sea posible, es necesario que tales impuestos sean satisfechos directamente por el máximo de individuos que se beneficien de los servicios previstos por los gobiernos locales".

Tanto la formulación de la cooperación que se recoge en los artículos 57 y 58 de la LBRL, como la de cooperación, ya sea funcional u orgánica, expresadas en los artículos 10.2, 59 y 62 de la LBRL, se orientan, en los términos recogidos en la STC 214/1989:

"flexibilizar y prevenir disfunciones derivadas del propio sistema de distribución de competencias aunque sin alterar, en ninguno de los casos, la titulación y el ejercicio de las competencias propias de los entes en relación, lo cierto es que las consecuencias y efectos dimanantes de unas y otras no son equiparables. La voluntariedad en el caso de la cooperación frente a la imposición en la coordinación -ya que todo coordinación conlleva un cierto poder de dirección, consecuencia de la posición de superioridad en que se encuentra el que coordina respecto al coordinado, es, por si mismo, un elemento diferenciador de primer orden, lo que explica y justifica que, desde la perspectiva competencial, distintas hayan de ser las posibilidades de poner en práctica unas y otras fórmulas"

Resulta sugestivo plantear los mecanismos de coordinación que se utilizan por la Unión Europea dada la relevancia que tienen los actores locales en el 
mismo. El Método Abierto de Coordinación basado en los mecanismos del soft law plantea una racionalización y refinamiento de los diferentes procesos de intervención. Parte de la definición efectuada por el Consejo de Europa en la Cumbre de Lisboa en relación con la Estrategia de empleo cuyos cuatro principios son aprendizaje mutuo, establecimiento de indicadores, evaluación de mejores prácticas y presión equitativa para la consecución de objetivos.

Este método parte de la definición precisa de los objetivos comunes que rige la política pública con específicos calendarios para su implantación en el corto, medio y largo plazo, estableciendo indicadores cualitativos y cuantitativos y referencias estadísticas sobre la comparación de las mejores prácticas al objeto de presionar, y en definitiva lograr la consecución, de las políticas públicas previamente definidas. Sobre esta base se elaboran los planes de actuación que son monitorizados mediante la evaluación, y revisión de los indicadores. Finalmente la decisión en materia de coordinación no puede suponer una carga adicional para los entes coordinados de forma que los costes derivados de la implantación de estos acuerdos deben ser asumidos por la Administración coordinadora.

\section{LA GOBERNANZA GOMO SOLUGIÓN A LA "CRISIS DE GOBERNABILIDAD"}

El gobierno en red. Como es sabido las transformaciones derivadas de las limitaciones y críticas a la burocracia como paradigma de racionalidad administrativa dieron paso al modelo gerencial o neoempresarial cuya corriente mayoritaria fue la conocida como "Nueva Gestión Pública". La insuficiencia de este modelo ha dado lugar a lo que hoy se denomina Gobernanza [38].

Este término, ligado en principio a los proyectos de ayuda al desarrollo ha ampliado su espacio de significación a todos los niveles de gobierno y gestión públicas. La propia Guía para el acceso a los servicios básicos de la ONU aprobada en abril de 2009 se refiere a la Gobernanza en su doble dimensión: política y técnica (I.9) y junto a los requerimientos de cada una señala que ambas exigen transparencia y participación de todas las partes involucradas promoviendo políticas (y agendas adecuadas) para la implantación de los servicios básicos para todos. En esta misma línea se expresa el Libro Blanco de la Unión europea [21] (COM 2001/248).

La gobernanza es por tanto un nuevo estilo de gobernar, una puesta en práctica de modos más cooperativos en los que parece difuminarse los límites 
entre los sectores público y privado, en el que se interactúa en redes integradas por actores públicos y privados que se observan en niveles específicos, que llevan a cabo prácticas de intercambio, coordinación, control y adopción de decisiones autónomos y en red superando la exclusividad de las instituciones y reconociendo la pluralidad de actores sociales induciendo su participación y cooperación. La idea de la Gobernanza ve en la sociedad misma el problema que tiene que resolver y no tanto una defectuosa técnica administrativa por la que se trata de implicar a los actores sociales en la solución de los problemas, motivarlos y activarlos, para no convertirlos en ciudadanos dependientes o en clientes irresponsables [29]. De hecho, los principios de la gobernanza son la apertura, la participación, la responsabilidad, la eficacia y la coherencia [38].

Quizás una de las más esclarecedoras definiciones del modelo de gobernanza sea el de gestión de redes [31], entendiendo que en realidad sólo existe una red cuando se establecen y utilizan sistemáticamente (gerencia) vínculos internos y externos (comunicación, interacción y coordinación) entre gente, equipos y organizaciones (nodos) con la finalidad de mejorar el desempeño administrativo. En esta línea la OCDE ha elaborado unas primeras directrices estratégicas para la gestión de redes de interés público ${ }^{20}$.

${ }^{20}$ OECD, Local Partnership for Better Governance, París, 2001: Asegurar que las metas de política propuestas para la red son consistentes a nivel central entre los diferentes departamentos y agencias de las Administraciones implicadas. Las redes no deben responder sólo ante un departamento o agencia, sino ante todos los que resulten necesarios para el logro de sus propósitos. Los interactuantes en la red deben tener claro cuál es su papel en la formulación e implementación de la política o servicio de que se trate.

Adaptar el marco estratégico de la red a las necesidades de los intervinientes. La red sólo tiene sentido si cada uno de los intervinientes puede mejorar sensiblemente su responsabilidad específica, ya sea como gerente público, empresa, asociación cívica, institución académica, etc. Para ello es necesario transparentar tanto la contribución de cada parte la estrategia común de la red como el aporte que de ésta podrá derivar cada una.

Fortalecer la responsabilidad de los participantes. Ello exige que la gestión de la red no sólo defina la función de planificación estratégica, apreciación de proyectos o provisión de asistencia, sino que transparente además quién hace qué, quien representa a quién, quién responde de qué y ante a quién; en una palabra, un mecanismo eficaz de distribución de responsabilidades. Si las redes se convierten en un mecanismo de dilución de responsabilidades, quedará en pie pocas de las virtudes que se postulan de las mismas.

La flexibilidad de la gestión de los programas públicos es una condición pare el buen funcionamiento de las redes. Esta flexibilidad no impide un marco claro de distribución de funciones y responsabilidad entre las Administraciones Públicas, responsables últimas de los servicios públicos, y las redes de agentes diversos implicados en su mejor producción efectiva. Garantizar la flexibilidad de la red y la unidad de dirección política está dando paso a interesantes tendencias. 
Hay que tener en cuenta, en el caso español, que entre los dos modelos que nuestra Constitución establece en su artículo 23.1 del derecho de participación ciudadana en los asuntos públicos, nuestro ordenamiento jurídico ha dado prioridad al de democracia representativa estando excesivamente constreñidos los mecanismos de democracia directa o participativa contraviniéndose así las indicaciones del artículo 9.2 de la Constitución cuando se conmina a los poderes públicos a facilitar la participación de los ciudadanos en la vida política, económica, cultual y social.

En el nivel local la implantación de los sistemas de gobernanza son plenamente viables -ya se están utilizando en la elaboración de determinados presupuestos participativos- e implican una profundización democrática en clave deliberativa que desde el punto de vista legislativo entendemos corresponde ahora promover y fomentar, aunque sus resultados sociales no puedan verse a corto plazo y pese a su crítica, no exenta de sentido [49], lo cierto es que el propio Consejo de europa ${ }^{21}$ ha afirmado que los principios que integran y constituyen la gobernanza local son necesarios para la consecución de un buen gobierno que responda a las expectativas y necesidades de los ciudadanos y que se concreta en que se ejerza responsablemente la autoridad pública en coordinación con las demandas de los vecinos ofreciendo servicios de calidad [30].

La economía de la experiencia. Esta transformación del modelo de gestión gerencial al nuevo modelo de gestión pública encuentra su reflejo en el ajuste que se está produciendo en las organizaciones que ven como surgen nuevos tipos eclécticos e innovadores en lo que se viene denominando un «escenario líquido» [6] sobre la base de lo que Joseph Pine y James H. Gilmore calificaron como «La economía de la experiencia» 22 . El concepto de gestión, de organización gerencial, de la «economía de la dirección» basado en las cuatro «c»-continuidad, constancia, coherencia, consistencia- está trans-

\footnotetext{
${ }^{21}$ Otros textos de las instituciones comunitarias sobre la gobernanza local además de las Comunicaciones de la Comisión europea son: Resolución del Parlamento Europeo (PE326.790), Dictamen del Comité de las Regiones «La gobernanza en el consenso europeo sobre la política de desarrollo» (2007/C 197/09, Carta de la UE sobre apoyo a la gobernanza local. Programa comunitario «Europa para los ciudadanos»

${ }^{22}$ B.J. Pine and J.H. Gilmore, The Experience Economy: Work is Theatre and Every Business is a Stage, Harvard Business School Press, 1999 (trad. cast.: La economía de la experiencia, Barcelona, Granica, 2002).
} 
formándose en una organización basada en la «economía de la experiencia» representada por la inmediatez, la subjetividad, la diversión y la representación, que supone una superación del modelo que Max Weber consideró como el nacimiento de la modernidad. En este contexto, Zygmunt [6], está realizando un lúcido análisis de esta situación ${ }^{23}$.

\section{NOTAS PARA UNA LEGISLACIÓN DE AUTONOMÍA LOCAL}

En los años que se han sucedido desde la aprobación de la Ley 7/1985, de 2 de abril, se ha producido un claro distanciamiento entre los discursos políticos, lleno de referencias a la autonomía local, a la participación, o a la transparencia y la propia realidad jurídica (y económica) en la que se desenvuelven las entidades locales españolas. Se aprecia que se ha dejado pasar una oportunidad, acuciados por una realidad muy dinámica en un contexto de descentralización autonómico, para destacar las potencialidades de la autonomía local y reforzar los presupuestos para su ejercicio lo que hubiera supuesto una notable profundización democrática.

Desde esta perspectiva se indica, a título enunciativo entre otras, las siguientes deficiencias en el ámbito de las Entidades Locales:

a) Marginación en la elaboración de las normas generales, en las que las entidades locales carecen de participación efectiva.

b) Atribución de competencias sin asignación de recursos suficientes, o competencias de escasa calidad.

c) Hiperregulación normativa que deja sin margen la autorregulación local.

\footnotetext{
${ }^{23}$ Unas cuantas funciones, que hasta ahora se consideraban que pertenecían al dominio del puesto de trabajo, se han «subcontratado» a los «cooperadores» y se han sustituido en consecuencia por relaciones de tipo de mercado (al estilo de «si no queda plenamente satisfecho, devuelva el producto a la tienda») o subsidiarizadas» a cada empleado de forma individual, pasando de este modo la responsabilidad por el rendimiento, y la obligación de soportar las consecuencias, de los hombros de los jefes a los de los empleados. Hoy, el símbolo del verdadero dominio es la facilidad con que se evita la realización de tareas ortodoxas de gerencia, que han sido cedidas a un lado o han descendido en la jerarquía.
} 
d) Concurrencia competencial de administraciones sobre las mismas materias, con prevalencia de las decisiones de órganos autonómicos no elegidos directamente.

e) Financiación mediante transferencias condicionadas.

f) Escaso interés de los partidos en la selección y presentación de representantes idóneos para los puestos de gestión política.

f) Vaciamiento efectivo del poder resolutivo local, o con un margen muy reducido de autonomía decisoria.

g) Y, de forma muy relevante en éstos momentos, la utilización de las Entidades Locales como meras agencias o extensiones de las otras administraciones territoriales a las que se les asigna la realización de meras tareas burocráticas sin margen de autonomía o gestión.

\subsection{Una administración eficiente}

No es objeto de este trabajo el estudio de la problemática de la financiación local que constituye un tema central en el debate municipalista -aunque nos llame la atención que los recursos propios fundamentales de las Entidades locales recaigan casi en exclusiva, sobre la propiedad privada de los ciudadanos (Impuesto Bienes Inmuebles, Impuesto de Incremento del valor de los terrenos, Impuesto de circulación de vehículos)-. Pero si se pretende efectuar unas breves consideraciones acerca de la eficiencia en gasto de los gobiernos locales sobre la base de algunos estudios que se están efectuando en el derecho comparado.

La Constitución española al definir en su artículo 103.1 los principios de actuación de la Administración Pública no recoge el principio de eficiencia, la Administración Pública, recoge, sirve con ob jetividad los intereses generales y actúa de acuerdo con los principios de eficacia, jerarquía descentralización, des-concentración y coordinación con sometimiento pleno a la Ley y al Derecho. El principio de eficiencia se ha introducido en el artículo 3.2 de la Ley 30/1992, de 26 de noviembre, de Régimen Jurídico y Procedimiento Administrativo Común y alude a él el artículo 133 de la Ley de Bases de Régimen Local al, entre los criterios de la gestión económico financiera, la asignación de recursos con arreglo a criterios de eficiencia, que se hará en función de la eficacia y cumplimiento de objetivos.

Hay que partir que en la materia de Administración local en España la mayoría de los datos están disgregados, no existe un banco de datos común que 
nos permita conocer de forma fiable los indicadores de gestión en los servicios que se están prestando, cuáles son los estándares objetivos, tan sólo los datos relativos a la contabilidad presupuestaria se encuentran homogeneizados, debiéndose acudir a informes especiales realizados por diversas entidades públicas (Cámaras de Cuenta, Defensores del Pueblo, Institutos Universitarios, etc.) o privadas (Observatorios de Gobierno local, Centros de Estudios o Fundaciones) para conocer mediante indicadores el estado o situación de cada entidad y los datos comparados, datos que empiezan a ser obtenidos a través de Cartas de servicios. Finalmente se están desarrollando rankings de ciudades en relación con la transparencia, la calidad de vida ${ }^{24}$, el grado de satisfacción de sus vecinos ${ }^{25} \mathrm{O}$ la protección del medio ambiente ${ }^{26}$ cuyos resultados son controvertidos ${ }^{27}$.

Por eso para analizar la eficiencia del gasto público en los gobiernos locales tenemos que acudir a los trabajos que se están llevando a cabo en otros países. Un buen ejemplo es el que se basa en el sistema de medida que se lleva a cabo en los gobiernos locales ingleses a través del denominado "Comprehensive Performance Assessment" (CPA) introducido en 2002 al objeto de determinar el grado de prestación de los servicios públicos por los Ayuntamientos cuya realización se encomienda a auditores externos (the Audit Commision).

Otros ejemplos son los que se están llevando a cabo en Estados Unidos a través de metodología alternativas como, por ejemplo Data envelopment analysis (DEA) [35]. O el que se está llevando a cabo en Portugal mediante la metodología Free disposal hull (FDH) [5]. Citamos estos tres supuestos ya que en los tres métodos (CPA; DEA; FDH) y tres diferentes países (Gran Bretaña, Estados Unidos y Portugal) las investigaciones efectuadas han dado el mismo paradójico resultado: gastando más se obtiene menos, así, en el caso de Gran Bretaña [46] no consta que un mayor gasto suponga una mejora sustancial ${ }^{28}$.

${ }^{24}$ Economist Intelligence Unit, Monocle Magazine, Mercer quality of life surveys.

${ }^{25}$ Urban audit perception survey, Local perceptions of quality of life in 31 european cities. U.E., 2004.

${ }^{26}$ World Bank.

${ }^{27}$ Joel Kotkin: Why the "Liavable Cities" Rankings Are Wrong”, Forbes, agosto 2009.

28 The empiricaul analysis provides no evidence that higer public spending translates into better performance. Rather, the estimate of effect of excess spending on performance is negative 
La misma conclusión se alcanza en el estudio elaborado en la Región de Lisboa y el Valle del Tejo en orden a estimar la extensión de los gastos y si los mismo suponen un derroche o una buena práctica ${ }^{29}$.

Los estudios reseñados, en especial el caso de Gran Bretaña demuestran que la publicación de los resultados, y el conocimiento por los ciudadanos del nivel de eficacia de sus Entidades locales - en relación con otras-, supone ya un incentivo automático para que los poderes locales implanten sistemas de mejora en los procesos tanto de producción como de gestión de los servicios públicos y adopten medidas para luchar contra la ineficiencia y el exceso de gasto, y estas medidas se adopten en un contexto de equidad. Este mismo efecto se puede observar en la realización de otras auditorías o análisis como el realizado en materia de Transparencia de los Ayuntamientos ${ }^{30}$.

\subsection{Una administración transparente}

La lucha contra la corrupción, promover la transparencia, difundir la información de que se disponga, rendir cuentas constituye hoy una exigencia en la prestación de los servicios públicos, no solo de los países con democracias incipientes sino aún más en las democracias avanzadas. Un ejemplo en este último caso es el movimiento Change Congress iniciado en Estados Unidos por el influyente abogado Lawrence Lessig - uno de los defensores del copyleft y fundador del movimiento Commons Creative en la era digital- que ha publicado la Declaración por la Independencia ${ }^{31}$, que propugna, en el ámbito de la lu-

ina random effects ordered prohibit specification. Morover, controlling for correlation between jurisdiction specific effects and regressors and for fixed characteristics of a locality -including institutional structure and socio-economic complexion porvides further evidfence in support of the hypothesis that public expenditures in excess of centrally set standards have a detrimental effect on performance.

29 The effciency results measured in terms of input and output effciency scores suggest that, on average, the region of Lisbon municipalities could be characterised as being relatively ineffcient.Among the 51 municipalities asessed we found that they could have achieved, on average, roughly the same level of local output with about 39 percent fewer resources, i.e., that local performance could be imporved without necessarily increasing municipal spending.

30 Índice de transparencia de los Ayuntamientos, resultados 2009, aspectos más destacados, http://www.transparencia.org.es.

${ }^{31}$ ADeclaration for Independence, Lawrence Lessig. 
cha contra la corrupción, la publicación, entre otros datos, de la contabilidad de los partidos políticos.

La situación a la que se ha llegado deriva de la confusión que a partir de los años 70 se produce entre capitalismo - o supercapitalismo- y democracia como consecuencia de la aparición de grandes empresas más competitivas, globales e innovadoras. En esta transformación nuestra capacidad como consumidores e inversores ha mejorado significativamente pero a costa de nuestras capacidades, como ciudadanos, en la búsqueda del bien común [44]. La reacción frente a esta confusión se ha producido después ${ }^{32}$.

Un ejemplo en la evaluación de la transparencia de la Entidades Locales españolas es el denominado Índice de Transparencia de los Ayuntamientos (ITA) anteriormente citado que se está elaborando por la Organización No gubernamental denominada Transparencia Internacional en España para medir el nivel de transparencia ante los ciudadanos y la sociedad de los Ayuntamientos españoles. El primer año de aplicación del ITA 2008 en el cual se evaluó la transparencia de los 100 mayores Ayuntamientos de España, y a través de un conjunto integrado de 80 indicadores alcanzando el año 2009 a 110 municipios españoles.

\subsection{Una administración sin trabas}

Afinales del año 2009 los Ayuntamientos se empezaron a enfrentar a dos retos, por un lado la plena implantación de la Ley 11/2007, de 22 de junio, de acceso electrónico de los ciudadanos a los Servicios Públicos, y, por otro, la transposición de la Directiva 2006/123, del Parlamento europeo y del Consejo relativa a los servicios del mercado interior cuyas repercusiones administrativas tiene carácter estructural ya que el principio general que inspira la misma es la prohibición de intervenciones autorizatorias de carácter previo.

32 The first and most important step is to have a clear understanding of the appropriate boundary between capitalism and democracy -between the economic game, and how its rules are set- so that the boundary can be better defended. Companies are not citizens. They are bundles of contracts. The purpose of companies is to play the economic game as aggressively as possible. The challenge for us as citizens is to stop them form setting the rules. Keeping supercapitalism from spilling over into democracy is the only constructive agenda for change. 
En cuanto al primero, la implantación de las tecnologías de la información que permitan a los ciudadanos a ejercer el derecho de relacionarse por medios electrónicos, supone la obligación de la Administración, al servicio del ciudadano, de transformarse en una administración electrónica utilizando, para ello, tecnologías de la Información y el conocimiento bajo los criterios de: disponibilidad, accesibilidad, integridad, autenticidad, confidencialidad y conservación de los datos, informaciones y servicios que gestione y conlleva los siguientes derechos a favor de los ciudadanos.

Por su parte, la transposición de la Directiva 2006/123, del Parlamento europeo y del Consejo relativa a los servicios del mercado interior que tiene por objeto «eliminar los obstáculos que se oponen a la libertad de establecimiento de los prestadores de los Estados miembros y a la libre circulación de servicios entre los Estados miembros y garantizar, tanto a los destinatarios como a los prestadores de los servicios, la seguridad jurídica necesaria para el ejercicio efectivo de estas dos libertades del Tratado» (Preámbulo).

En este sentido algunos autores [10] han planteado que «el principio que sienta la Directiva es el de innecesariedad de autorizaciones previas; este principio solo es excepcionable cuando el régimen de autorización que se establezca esté justificado por una «razón imperiosa de interés general», no suponga discriminación para el prestador de servicios de que se trate, y siempre que el objetivo perseguido no se pueda alcanzar con una medida menos restrictiva ${ }^{33}$.

La transposición de la Directiva ya se anuncia como un proceso muy lento, complejo, sembrado de conflictos, que tendrá que despejarse poco a poco

${ }^{33}$ Para la correcta incorporación de esta exigencia se obliga a los Estados miembros a identificar los regímenes autorizatorios vigentes en cualquier ámbito de gobierno (en nuestro caso estatal, autonómico o local), y comprobar si las autorizaciones reguladas cumplen con los criterios señalados a través de un procedimiento de evaluación recíproca al que más adelante nos referiremos. En un segundo nivel de análisis se sitúan los criterios y condiciones de los regímenes en autorización que hayan superado el primer filtro señalado en el párrafo anterior. El art.10 de la Directiva señala que los criterios de concesión o denegación de la autorización correspondiente no podrán incorporar facultades de apreciación de las autoridades competentes que no estén delimitados en forma tal que se garantice que el ejercicio de las mismas no sea arbitrario. Salvado ese primer límite, se establecen las características generales a las que deben atenerse los criterios de decisión (claridad, objetividad, transparencia, accesibilidad...), entre los que destacamos dos: $1 .{ }^{\circ}$ Estar justificados por una razón imperiosa de interés general. $2{ }^{\circ}$ Ser proporcionados a dicho objetivo de interés general. 
ante los Tribunales internos y Comunitario europeo según pronostica Santiago Muñoz Machado [33] derivadas de la falta de uniformidad conceptual, o la diferente evaluación de la proporcionalidad, la distinta apreciación de los límites de claridad y objetividad a que deben subordinarse los regímenes de autorización que subsistan etc.pero lo cierto es que nos encaminamos no sólo a la simplificación de los procedimientos de intervención y decisión, o a la tramitación de los expedientes y la cooperación entre autoridades administrativas a través de la ventanilla única, o la mejora de la información de los usuarios e interesados y la incorporación de nuevas tecnologías de información, sino, sobre todo, al cambio del régimen d e autorizaciones administrativas que supongan restricciones a la libertad de establecimiento y de prestación de servicios.

Este proceso, cuyas dificultades se producirán especialmente en los Ayuntamientos, al ser los que articulan mayores actuaciones de intervención administrativa sobre las actividades de los ciudadanos [16] y mayor interacción entre ellos.

\subsection{Una administración sin cargas}

Recuerdo hace años leer un artículo en El Consultor de Lago Santistéban sobre las cargas estatales en la Administración Local. Se identificaban un listado de materias en el que las Corporaciones Locales prestaban servicios a otras administraciones sin contraprestación ni justificación lógica alguna. Eran ya, en los inicios democráticos, vestigios de una administración local de herencia francesa: la articulación del ente local dentro de la voluntad general del Estado con la construcción del concepto de pouvoir municipal.Esta construcción jacobina se tuvo que enfrentar a la influencia del conocimiento que tuvieron los ilustrados exiliados a Inglaterra del selfgovernment del municipalismo inglés, con ella se introdujo la aspiración democrática de que los poderes locales fuesen elegidos por los vecinos [36].

Estas cargas estatales, con excepción de las tareas de reclutamiento, no sólo no han disminuido sino que se han visto incrementadas desde entonces. Lo único que ha cambiado es el nombre, ahora son cargas autonómicas.

Son muchos los ejemplos que se pueden traer a colación de estas cargas que subsisten y han venido colmatando en muchos casos la actividad municipal. Otras están apareciendo en los últimos tiempos, en formas de Decretos leyes e incluso Órdenes por las que se "usan" las entidades locales como agencias estatales o autonómicas, ya sea para el empadronamiento con carácter retroactivo al objeto de realizar regularizaciones de extranjeros, ya para la eje- 
cución de obras no previstas ni planificadas en los presupuestos municipales que se consideren urgentes en aras de la creación de empleo, ya para tramitar solicitudes ante otros organismos, o ser meros registros de peticionarios o demandantes de servicios.

Pongamos tres breves ejemplos, uno referido a una atribución histórica, el de mantenimiento de centros escolares, otra, más reciente, el sufragar cuerpos policiales coordinados por otra administración, y finalmente, el relativo a la prestación de los servicios sociales.

El Mantenimiento de Centros Escolares. Siguiendo con el supuesto de Andalucía, la Ley 7/1999 de 29 de septiembre de Bienes de las Entidades Locales señala que son de titularidad de las Entidades Locales los edificios públicos destinados a centros de educación infantil, de segundo ciclo, primaria o especial pero, ¿para qué? Conforme a la disposición adicional primera de la Ley estos edificios no pueden destinarse a otros servicios o finalidades sin autorización previa de la administración educativa correspondiente. La razón se encuentra en el Decreto 155/1997, de 10 de junio, por la que se asigna a los $\mathrm{Mu}-$ nicipios la conservación, mantenimiento y vigilancia de los edificios propios o dependientes destinados íntegramente a centros de educación infantil de segundo ciclo, primaria o especial. Es decir que corresponde a los ayuntamientos gestionar la limpieza diaria, efectuarlas reparaciones y sustituciones ordinarias, dotar estos centros de conserjes y vigilancia. Y ello sin contar que muchos ayuntamientos también han construido los centros, ya sean los de su titularidad, ya sean de secundaria o bachillerato en base a Convenios interadministrativos con la Consejería de Educación para atender las demandas de la población. La pregunta es ¿qué margen de autonomía cabe en esta atribución? Y la respuesta es que depende de cada Ayuntamiento la frecuencia e intensidad de la limpieza, y los recursos humanos y materiales que se deban dedicar siendo ajena la Administración educativa de la infraestructura donde se organiza el servicio.

El mantenimiento de Cuerpos de Policía local «autonómicos». Uno de los rasgos más característicos de la existencia de un Ayuntamiento es que cuenta con los servicios de un Cuerpo de Policía Local, de cuyo número actual de efectivos en el territorio nacional, por cierto, no existen datos oficiales ${ }^{34}$.

34 «¿Sabe alguien cuántos policías municipales hay? La Administración no sabe, no contesta. El País 18/03/2007.

Los escasos datos sobre el número de agentes de la Policía local y la evolución de los Cuerpos de Policía Local han sido recopilados por Don José Escalante Castarroyo en diversas publi- 
El artículo 149.1.29 de la Constitución atribuye al Estado la competencia exclusiva sobre la seguridad pública salvo en aquellas comunidades que por Estatuto tienen prevista la creación de policías autonómicas propias, siendo muy limitada la competencia que, en calidad de coordinación de policías locales se atribuye al resto de Comunidades. Su justificación, desde el punto de vista del régimen local, se encuentra en el artículo 25 de la Ley 7/1985, de 2 de abril, reguladora de las bases de Régimen Local por el que se reconoce competencias a los municipios en materias de seguridad en lugares públicos y de ordenación del tráfico de personas y vehículos en las vías urbanas. Sin embargo, su régimen regulatorio se recoge en la Ley Orgánica 2/1986, de 13 de marzo, de Fuerzas y Cuerpos de Seguridad, en cuya Exposición de Motivos se recoge que "Por lo que respecta a las funciones, dado que no existe ningún condicionamiento constitucional, se ha procurado dar a las Corporaciones Locales una participación en el mantenimiento de la seguridad ciudadana, coherente con el modelo diseñado, presidido por la evitación de duplicidades y concurrencias innecesarias yen función de las características propias de los Cuerpos de Policía Local y de la actividad que tradicionalmente vienen realizando". Sin embargo de la lectura del artículo 53 que recoge las competencias de la Policía Local, la materia de seguridad ciudadana que es la que representa mayor importancia para las Corporaciones Locales, cuenta con unas competencias muy limitadas ${ }^{35}$, la mayoría

caciones así como a través de estudios comparados (La nueva Policía local mancomunada, José María Mainar Ene, El Consultor 18, 2008) de los que se desprenden, entre otros datos, que en estos momentos el número de agentes de la Policía Local podría superar el de la Policía Nacional, distribuidos en unos 1.700 Cuerpos de Policía con una amalgama organizativa y estructural, de los que casi 200 cuentan con un sólo miembro.

${ }^{35} \mathrm{El}$ elenco de funciones que se atribuyen expresamente a la Policía Local en el artículo 53 de la Ley Orgánica 2/1986 es el siguiente: a) Proteger a las autoridades de las Corporaciones Locales, y vigilancia o custodia de sus edificios e instalaciones. b) Ordenar, señalizar y dirigir el tráfico en el casco urbano, de acuerdo con lo establecido en las normas de circulación. c) Instruir atestados por accidentes de circulación dentro del casco urbano. d) Policía Administrativa, en lo relativo a las Ordenanzas, Bandos y demás disposiciones municipales dentro del ámbito de su competencia. e) Participar en las funciones de Policía Judicial, en la forma establecida en el artículo 29.2 de esta Ley. f) La prestación de auxilio, en los casos de accidente, catástrofe o calamidad pública, participando, en la forma prevista en las Leyes, en la ejecución de los planes de Protección Civil. g) Efectuar diligencias de prevención y cuantas actuaciones tiendan a evitar la comisión de actos delictivos en el marco de colaboración establecido en las Juntas de Seguridad. h) Vigilar los espacios públicos y colaborar con las Fuerzas y Cuerpos de Seguridad del Estado y con la Policía de las Comunidades Autónomas en la protección de las manifestaciones y el mantenimiento del orden en grandes concentraciones humanas, cuando sean requeridos para ello. i) Cooperar en la resolución de los conflictos privados cuando sean requeridos para ello. 
de las cuales no justifican la necesidad de contar con un "Institutos armados de naturaleza civil, con estructura y organización jerarquizada", pudiendo ser prestadas por empresas de servicios o funcionarios propios habilitados para la inspección y denuncia de infracciones administrativas.

Se trata pues de Cuerpos hiperregulados ${ }^{36}$ cuyas funciones principales se han convertido en accesorias, siendo su actividad real la de colaborar con las Fuerzas y Cuerpos de Seguridad del Estado a quienes le corresponde la seguridad pública. Junto a ello a través de estos Cuerpos se atribuye a los municipios cabeza de partido judicial la carga de disponer de los denominados depósitos de detenidos a disposición judicial (que durante algún tiempo han venido también cumpliendo los servicios de arrestos de fin de semana), o que a la policía local se le encomiendan funciones de control del cumplimiento de las penas en los domicilios de las personas que conforme al artículo 37 del Código Penal son condenadas a la pena de localización permanente ${ }^{37}$. Podemos concluir que el margen de autonomía local para organizar estos Cuerpos es prácticamente irrelevante, y, en el que queda, la excesiva proximidad entre el gobernante y el gobernado hacen aconsejable la atribución de competencias a una administración más distante ${ }^{38}$.

${ }^{36}$ Por la Comunidad Autónoma de Andalucía, por ejemplo, en base a las funciones de coordinar la actuación de las Policías Locales en el ámbito territorial de la Comunidad, atribuida por la Ley Orgánica 2/1986 se han dictado disposiciones que regulan desde las medias panty hasta los botones de la guerrera (Orden de 16 de febrero de 2009 publicada en el BOJA núm. 42, de 3 de marzo) y en la que resulta muy difícil identificar, sino es a través de un mínimo escudo, el Ayuntamiento de pertenencia, el que corre con todos los gastos derivados de la funciones del Policía Local.

${ }^{37}$ En el Informe efectuado por el Defensor del Pueblo Andaluz en diciembre de 2008 sobre "Lugares de custodia de personas detenidas: Depósitos municipales y otros calabozos policiales" se concluye: "Así las cosas, creemos sinceramente que ha llegado el momento de que por parte del Ministerio del Interior, al que se atribuyen, recordémoslo, no sólo las competencias penitenciarias sino también la administración general de la seguridad ciudadana y el mando superior de las Fuerzas y Cuerpos de Seguridad del Estado, se promueva un cambio legislativo tendente a derogar la Disposición Final Quinta de la Ley de Bases de Régimen Local, Ley 7/1985, de 2 de Abril, de tal modo que el Servicio de Depósito de Detenidos a disposición judicial pase a ser gestionado directamente por el Cuerpo Nacional de Policía y la Guardia Civil, y en sus propias instalaciones".

${ }^{38}$ Según el Proyecto de Ley de modificación de la Ley de Tráfico publicado en el Boletín Oficial de las Cortes Generales el 5 de diciembre de 2008 estima unos quince millones de procedimientos sancionadores por infracción d ela normativa de circulación. De acuerdo a los datos de la Dirección General de Tráfico en 2008 se instruyeron tres millones y medio de procedimien- 
Y, por último, una pregunta: ¿Que ha sido de la elaboración de una norma que defina y concrete el ámbito de participación de la policía local en materia de mantenimiento de la seguridad ciudadana, como policía de proximidad, así como en el ejercicio de las funciones de policía judicial como preveía la Disposición Adicional Décima de la Ley 7/1985, de 2 de abril (Añadida por art. 1.3 de Ley 57/2003, de 16 diciembre)?

La prestación de los Servicios Sociales. Un caso paradigmático de la situación en la que se encuentran las competencias locales es en materia de servicios sociales o prevención social ateniéndonos a que el Estatuto reconoce una competencia compartida con el Estado en el marco del artículo 149.1.1 de la Constitución en los artículos 61 -servicios sociales, voluntariado menores y familia-, artículo 62.1 -inmigración, políticas de integración y participación de inmigrantes- y artículo 73 - políticas de género- y 74 -políticas de juventudconteniendo una habilitación genérica, el artículo 84, a la Comunidad Autónoma para organizar y administrar todos los servicios con sanidad, educación y servicios sociales y ejercerá la tutela de las instituciones y entidades en estas materias sin perjuicio de la alta inspección del Estado.

Por su parte la Ley de Bases de Régimen Local obliga en su artículo 26.1 c) a municipios de más de 20.000 habitantes, en el marco de la competencia genérica establecida en el artículo 25.2, competencia que se efectuará por sí o asociado con otros.

En este contexto resulta muy significativo, tal como resalta en la Revista Andaluza de Administración Pública [39], la redacción dada por los Estatutos de Cataluña y Andalucía en cuanto a la competencia en materia de Servicios Sociales. El artículo 31.1 del Estatuto Catalán reconoce a los Municipios unas determinadas atribuciones ${ }^{39}$.

tos por ese organismo correspondiendo el resto, más de diez millones, a los Municipios españoles. Sin embargo los países de nuestro entorno cuentan con sistemas automáticos de detección que supone un incremento del número de sanciones arbitrándose medios diferentes para el cobro de las multas -alternativos al procedimiento recaudatorio municipal- tales como la retirada de permisos, renovación de placas condicionada al pago de multas etc. Todo ello hace pensar si el tráfico no debía ser una competencia extraterritorial radicada en el ámbito europeo tal y como se deduce deL Proyecto de seguridad vial europeo PEPPER (Police Enforcement Policy and Programmes on European Roads) que está desarrollando la Base de Datos CLEOPATRA (Collection of Law Enforcement Operations and Police Activities To Reduce Traffic Accidents).

39 a) Estudiar y detectar las necesidades sociales en su ámbito territorial. b) Crear y gestionar los servicios sociales necesarios, tanto propios como delegados por otras administraciones, de 
El Estatuto de Andalucía, por el contrario reconoce las atribuciones ${ }^{40}$ a las que otorga carácter delegado, lo que supone, en materia de servicios sociales comunitarios, una regresión con relación a la atribución propia conferida por la legislación estatal.

En consecuencia, junto a la reducción competencial que se deriva del nuevo Estatuto, que atribuye a los municipios en lugar de competencias propias, competencias delegadas, y, en tanto se desarrollan nuevas leyes en la materia, la realidad es que los servicios sociales de atención básica, primaria o comunitaria que constituye "una estructura indispensable para consolidar y hacer progresar el "Estado del Bienestar" que la Constitución preconiza" tal y como resalta el Defensor del Pueblo [24] en el informe que se cita, y, en muchos casos también los servicios especializados, están siendo prestados de forma efectiva por los municipios sí, pero con una financiación insuficiente ${ }^{41}$.

acuerdo con la Cartera de servicios sociales y el plan estratégico correspondiente. c) Elaborar planes de actuación local en materia de servicios sociales y participar, su procede, en el plan de actuación del área básica correspondiente. d) Establecer los centros y servicios correspondientes al ámbito propio de los servicios sociales básicos. e) Promover la creación de los centros y servicios correspondientes al ámbito propio de los servicios sociales especializados y gestionarlos, en coordinación con la Administración de la Generalidad y el ente local supramunicipal correspondiente, de acuerdo con la cartera de Servicios sociales y el plan estratégico correspondiente. f) Colaborar con la Administración de la Generalidad en el ejercicio de las funciones de inspección y control en materia de servicios sociales. g) Ejercer las funciones que le delegue la Administración de la Generalidad. h) Participar en la elaboración de los planes yprogramas de la Generalidad en materia de Servicios Sociales. i) Coordinar los servicios locales, los equipos profesionales locales de los otros sistemas de bienestar social, las entidades asociativas y las que actúan en el ámbito de los servicios locales. j) Las que les atribuyan las leyes.

${ }^{40}$ Los Ayuntamientos serán responsables de los Servicios Sociales de su ámbito territorial, de acuerdo con la Ley reguladora de las Bases de Régimen Local, y dentro del marco de la presente Ley. Serán competencias de los Ayuntamientos por delegación de la Junta de Andalucía: a) La gestión de los Centros de Servicios Sociales Comunitarios en los municipios de más de 20.000 habitantes. b) La gestión de los Centros de Servicios Sociales Especializados de ámbito local, en los municipios de más de 20.000 habitantes. c) La ejecución y gestión de los programas de Servicios Sociales y prestaciones económicas que pudiera encomendarles el Consejo de Gobierno. d) Crear y gestionar los servicios sociales necesarios, tanto propios como delegados por otras administraciones, de acuerdo con la Cartera de servicios sociales y el plan estratégico correspondiente. e) Elaborar planes de actuación local en materia de servicios sociales y participar, su procede, en el plan de actuación del área básica correspondiente. f) Establecer los centros y servicios correspondientes al ámbito propio de los servicios.

${ }^{41}$ De acuerdo con el Informe especial efectuado por el Defensor del Pueblo de Andalucía en noviembre de 2005: "En este sentido, el mayor esfuerzo de financiación en estos diecisiete años 
Con independencia de la financiación local, el Plan Concertado de Prestaciones Básicas de Servicios sociales - algo muy parecido a una mera Encomienda de Gestión de las previstas en el artículo 15 de la Ley 30/1992, de 26 de noviembre, de Régimen Jurídico de las Administraciones Públicas y del Procedimiento administrativo común, por parte de las administraciones responsables con competencias propias a favor de las entidades locales- ha supuesto, por un lado, que la organización municipal cuente con unos recursos temporales para atenderlo - personal de programas y prestaciones-, que son renovados periódicamente, y a solicitar subvenciones para atender colectivos específicos y programas de atención especializada, bien de forma regular, o bien de manera improvisada, lo que implica que el sistema de Concierto se haya convertido en una situación de dependencia y subsidiariedad invertida, percibiéndose una cierta precariedad, inseguridad y falta de garantía en su prestación.

Muy similar ha sido la implantación de la Ley 39/2006, de 14 de diciembre, de Promoción de la Autonomía Personal y Atención de las personas en situación de dependencia, cuyo sistema distribuye las competencias únicamente entre la Administración General del Estado y las Comunidades Autónomas y se establecen los instrumentos de cooperación de ambas administraciones permitiendo la participación de las Entidades Locales en la gestión de los servicios de atención «de acuerdo con la normativa de sus respectivas Comunidades Autónomas y dentro de las competencias que la legislación vigente les atribuye» (artículo 12).

de funcionamiento del Plan Concertado (en el período 1988-2003) lo han realizado las Entidades Locales que han aportado el $62 \%$, a nivel andaluz, y el $54 \%$, a nivel estatal, del total de los recursos destinados a esta finalidad. La Junta de Andalucía, por su parte, ha aportado en esta Comunidad, un 23\% del total de estos recursos, mientras que en el resto del Estado la aportación Autonómica supone una media del 28\%. La Administración Estatal, a través del Ministerio de Trabajo y Asuntos Sociales, ha aportado, respectivamente, el 15\% del total de la financiación de Andalucía y el 18\% en el resto de España.

Por lo que se refiere a Andalucía, con respecto a las aportaciones de las tres Administraciones territoriales, el mayor compromiso de las Administraciones del Estado y de la Junta de Andalucía en los primeros años de andadura del Plan Concertado es objeto de decrecimiento de estas Administraciones y correlativo incremento del porcentaje de participación de las Corporaciones Locales en los años siguientes, lo que sitúa a éstas en los últimos ejercicios con cuotas que rondan los dos tercios de la financiación (66\%), frente al 20-22\% de la Junta de Andalucía y el 13$14 \%$ del Estado. Entre las Entidades Locales, corresponde el mayor peso a los Ayuntamientos (45-46\%), frente a las Diputaciones (2021\%), y entre los Ayuntamientos, ligeramente superior el correspondiente a los de más de 20.000 habitantes que a los de menor población). 
En el ámbito de Andalucía, por ejemplo, conforme al Decreto 168/2007, de 12 de junio, por el que se regula el procedimiento para el reconocimiento de la situación de dependencia y del derecho a las prestaciones del Sistema para la Autonomía y Atención a la Dependencia, así como los órganos competentes para su valoración, la participación de las Entidades Locales en el procedimiento (para el reconocimiento de la situación de dependencia y, en su caso, del derecho a las prestaciones del Sistema), consiste únicamente en la atribución a los Servicios Sociales Comunitarios correspondientes al municipio de residencia de las personas solicitantes del inicio de la tramitación del procedimiento para el reconocimiento de la situación (y, en su caso, del derecho a las prestaciones), así como la elaboración de la propuesta de Programa Individual de Atención (artículo 4.3). Básicamente, la recepción de la solicitud, recabar la subsanación en caso de no reunir los requisitos exigidos, y remitir al correspondiente órgano de valoración autonómico, que comunicará ya a la persona solicitante el día y hora en que los profesionales del citado órgano acudirán a su domicilio o lugar de residencia para efectuar la valoración. Es decir la participación se limita, básicamente, a contar con una ventanilla de recepción de documentación y su remisión al órgano competente. De esta forma podríamos decir igualmente, a partir de ahora, que el Servicio de Correos participa en la gestión de todos los servicios de acuerdo con la normativa de sus respectivas Comunidades Autónomas y dentro de las competencias que la legislación vigente les atribuye.

\subsection{Algunas propuestas}

Ante la inevitable interiorización del régimen local en el marco autonómico, salvo un imprevisible pacto de Estado entre las fuerzas políticas mayoritarias, nos enfrentamos, en esta fase de subconsitucionalización territorial, ante una reforma del Régimen Local vacía. Y ello porque Repensar lo local no significa únicamente modificar las estructuras, cambiar la forma de organización, establecer o suprimir competencias (que en ámbito municipal constituye servicios). Significa instar otras medidas de calado constitucional que en consecuencia, afectan al régimen orgánico: electoral, judicial, seguridad, etc, es decir conlleva un replanteamiento de todo el sistema legal establecido.

A nuestro juicio las reformas en marcha son una mera estratagema si no van precedidas de una prohibición de la financiación afectada de las Entidades Locales. Dotar a las Entidades Locales de medios suficientes y una participación justa y adecuada en los tributos estatales y autonómicos es el reconocimiento previo a lo que se ha planteado como segunda descentralización. Sin 
éste reconocimiento financiero previo no cabe margen para hablar de autonomía. Y asistimos en estos momentos a un incremento de políticas basadas en la subvención y tutela de las Corporaciones locales a través de las subvenciones y transferencias finalistas.

Por otro lado resulta oportuno que simultáneamente a la elaboración de la nueva ley se proceda a impulsar otras acciones, instar también a otros poderes públicos determinadas modificaciones, como a título de ejemplo la reforma policial apuntada al objeto de lograr una adecuada ubicación, especialización, capacidad técnica y coordinación de las distintas Fuerzas y Cuerpos de Seguridad que permita que las ciudades, con independencia de su tamaño o población constituyan espacios cívicos de sana convivencia social enfatizando para ello las políticas de prevención, inserción e integración, o la reforma judicial al objeto de lograr un mayor acercamiento de la Administración de Justicia a los problemas de convivencia y seguridad de los ciudadanas promoviendo la solución de determinados conflictos, en lugar de mediante lentos y costosos procesos, a través de formulas de arbitraje.

Ciñéndonos a los términos de las nuevas Leyes de Régimen Local, las de segunda generación, a título enunciativo y con carácter abierto se efectúan las siguientes propuestas que conllevarían a su vez modificaciones en la legislación estatal: a) Promover la superación del inframunicipalismo mediante fórmulas de fusión o supresión por incorporación de los Municipios que carezcan de recursos suficientes para la prestación de los servicios básicos, manteniendo su configuración como órganos desconcentrados bien en Entidades Locales Menores (o Autónomas) o mediante su integración como Distritos. Establecer como parámetro básico de prestación de servicios una población de 5.000 habitantes. b) Mejorar la definición de lo supramunicipal, de la cooperación municipal y de las redes de ciudades. c) Establecer una estructura básica o esencial junto con un catálogo abierto dejando a la libre opción municipal su elección y desarrollo de su estructura complementarias por corresponder ésta atribución, al amparo del artículo 137 de la Constitución, a cada entidad local. d) Designación del Alcalde mediante un sistema de elección directa a doble vuelta, vinculando la elección del Alcalde a la atribución de Concejalías y reforzando los instrumentos de control efectivo de las minorías. e) Reducir el número de Concejales y promover la calidad de los mismos. Se debe tender a un liderazgo innovador, se buscan «directores creativos» en organizaciones públicas. La visión de la ciudad, de los asuntos urbanos, debe ser como la del comisario (curator) de una exposición. f) Contemplar la posibilidad de suspensión temporal del cargo de Alcalde o Concejal en caso de procesamiento judicial. g) La normativa local debe tener un ámbito propio, debe ser expresión del poder 
local. La reserva de un espacio normativo no puede ser invadido en ejercicio de la libertad del legislador estatal y autonómico. h) La atribución de competencias propias debe ser directa, en lugar de una delegación de poderes, y, en función de ello, los mecanismos de control deben ser exclusivamente de legalidad. Suprimir cualquier remisión a la legislación sectorial a las que se les reservaría el establecimiento de estándares de calidad en la gestión de las competencias y servicios. i) Definir las competencias vinculadas a la titularidad municipal, por su objeto, las potestades destinadas a su ejercicio, los medios necesarios para su aplicación y los derechos - y deberes - de los ciudadanos en relación con las mismas. j) Recoger mecanismos de participación en las decisiones que afecten a las Entidades Locales así como mecanismos de coordinación de políticas y actividades administrativas mediante los procedimientos apropiados para garantizar la posición de autonomía de ambas partes en dicha cooperación. k) Implantar una gestión basada en sistemas de gobernanza tanto en su dimensión política como técnica, profundizando en una democratización deliberativa y participativa en la que tenga cabida la «gestión cívica» de competencias municipales, es decir, la participación efectiva de entidades, organizaciones y asociaciones ciudadanas sin ánimo de lucro en el ejercicio de competencias municipales, en la gestión de servicios y equipamientos. l) Diferenciación clara entre servicios públicos - definiendo cuáles son de prestación universal- y actividades económicas de los municipios, ya sean de carácter económico o social. m) Establecer el carácter público de las sesiones de todos los órganos de gobierno. n) Asegurar una Administración profesional con una combinación equilibrada entre cargos electos que lleven la dirección política y directivos profesionales que se ocupen de la gestión directa. o) Integrar en la normativa de régimen local las disposiciones de aplicación en desarrollo del Estatuto Básico del Empleado Público, con la posibilidad de desconcentrar y delegar funciones y atribuciones en cargos y órganos administrativos. p) Definición como órganos administrativos de los puestos atribuidos a los funcionarios con habilitación de carácter estatal (Secretaría, Intervención, Tesorería), por ser unidades administrativas a las que se les atribuyen funciones que tiene efectos jurídicos frente a terceros, o cuya actuación tiene carácter preceptivo eliminado su provisión (y cese), bajo el sistema de libre designación, al corresponderles propiamente funciones de control con dependencia funcional de las Cámaras de Cuentas. y, q) Finalmente las Comunidades Autónomas o el Estado deberían sufragar los gastos adicionales que para el ejercicio de las competencias propias por las Entidades locales pueda suponer la observancia de las reglas impuestas en uso de la potestad de coordinación por las otras Administraciones. 


\section{GONGLUSIÓN}

El vocablo municipium es una creación de fuentes jurídicas romanas. En un principio se denominaron así a las poblaciones fortificadas -el término municipium contiene el verbo munio que significa fortificar- que contaban con una organización y regulación propia, con vocación de convertirse en ciudades (civitates), frente a otro tipo de asentamiento como los fundus (menos numerosos, sin fortificación), los ager (del campo, de carácter rural), y las propias colonias fruto del expansionismo romano. La anexión de los municipios, su integración en la administración romana se efectuaba mediante el correspondiente tratado de forma que adquirían la condición de municipia foederata.

La etimología de la palabra municipio vinculada a la seguridad y protección del muro, de la muralla, a la garantía, integridad e identidad humana, también a la autoorganización y autogestión, y, finalmente, su configuración intermedia entre el campo y la ciudad, nos sirve como una metáfora final, que nos permita realizar una reflexión en profundidad sobre el rol o el papel que a estas instituciones les corresponde hoy.

El autor del presente trabajo tiene la convicción de que en los próximos años vamos a asistir al declive y desaparición del actual sistema municipal con el advenimiento de una estructura de ciudades, con un mayor o menor margen de autonomía, en un marco heterogéneo y de asociación transnacional, en el que la protección del campo,del Medio rural, se va a efectuar mediante Entidades supralocales, de ámbito comarcal o provincial.

Estos apuntes pretenden la superación del agostado término reforma, apostando sin ambages por una auténtica transformación: la definitiva conversión de los municipios en ciudades - con la consecuente conversión de sus vecinos en ciudadanos libres- en el marco de una democracia madura y avanzada, en un mundo equitativo y eficiente que tiende a la superación de fronteras, en el que todo está ya conectado, sincronizado, en red.

\section{REFERENCIAS}

[1] Los gobiernos locales en la construcción del futuro de los paises: Gobernanza Urbana y Desarrollo Regional. Consejería de Gobernación, Junta de Andalucía, 2009.

[2] Luciano Parejo Alfonso. La prevalencia del Derecho estatal sobre el regional. Centro de estudios constitucionales, 1981. 
[3] Luciano Parejo Alfonso. La modernización del gobierno local y sus consecuencias posibles para el régimen local básico implantado en 1985. Actualidad jurídica Aranzadi, (668), 2005.

[4] José Manuel Rodríguez Álvarez. La carta europea de la autonomía local y el pacto local. El Consultor, 10, 1999.

[5] Sónia Fernandes António Afonso. Efficiency of local government spending: Evidence for the lisbon region. ISEG/UTL. Technical University of Lisbon, 2003.

[6] Zygmunt Bauman. El arte de la vida. Paidós, 2008.

[7] Octavio Salazar Benítez. El sistema de gobierno municipal. Centro de estudios políticos y constitucionales, 2007.

[8] Julia Ortega Bernardo. Competencias, servicios públicos y actividad económica de los municipios. Revista de Administración Pública, 169, 2006.

[9] Yishai Blank. Localism in the new global legal order. Harvard International Law Journal, 47, 2006.

[10] Fernando Mora Bongera. La transposición de la directiva bolkestein, la liberta de establecimiento y las competencias de las entidades locales. El Consultor-La ley, 530, 2009.

[11] Francisco Velasco Caballero. Estatutos de autonomía, leyes básicas y leyes autonómicas en el sistema de fuentes del derecho local. Anuario de Gobierno Local, 1, 2005.

[12] Francisco Velasco Caballero. El estado de la autonomía local en 2007. Anuario de Derecho Municipal 2007, 2008.

[13] Francisco Velasco Caballero. Garantías estatutarias de la autonomía local. Contenios de la ley de régimen local de Andalucía. In Instituto de Derecho Local, UAM, 2008.

[14] Francisco Velasco Caballero. Derecho local. Sistema de fuentes. Marcial Pons, 2009.

[15] Francisco Velasco Caballero. Reformas en el derecho local: Qué y quién. Anuario de Derecho Municipal 2008, 2009.

[16] Antonio Reinoso Carriedo. La directiva de servicios. dificultades para su transposición. El Consultor-La ley, 2457, 2009.

[17] La coordinación de las políticas sociales en el ámbito municipal. Rafaela Artacho Gant. El Consultor, 6, 2008.

[18] Secretaría de Estado de Cooperación Territorial. Libro Blanco para la reforma del Gobierno Local. Ministerio de Administraciones Públicas, 2005.

[19] Consejería de Gobernación. Libro blanco de la administración local de Andalucía.

[20] Tomás de la Quadra-Salcedo Fernández del Castillo. Corporaciones locales, reforma de los estatutos y competencias estatales. Revista de Derecho Administrativo, 145, 2010. 
[21] Comisión de las Comunidades europeas. La gobernanza europea: Un libro blanco. 2001.

[22] Federación Andaluza de Municipios y Provincias. Documento base de posicionamiento ante una ley andaluza de régimen local, octubre 2008.

[23] Iñigo del Guayo Castiella. La gestión de los servicios públicos locales. Revista de Administración Pública, 165, 2004.

[24] Defensor del Pueblo Andaluz. Informe especial sobre la situación de los servicios sociales comunitarios en andalucía. 2005.

[25] Rafael Dios Durán. La organización del Gobierno de la Ciudad. Consejería de Gobernación, Junta de Andalucía, 2008.

[26] Jorge Fernández-Miranda Fernández-Miranda. El principio de autonomía local y la posible superación de la teoría de la garantía institucional.

[27] Casimiro López García. Las reformas del régimen local desde la ley $7 / 1985$, de bases de régimen local, hasta el nuevo proyecto de ley de bases de 2006. El Consultor, 5, 2008.

[28] Manuel Medina Guerrero. Competencias y financiación de los gobiernos locales. In Universidad de Sevilla, 2008.

[29] Daniel Innerarity. El nuevo espacio público. Espasa, 2006.

[30] María Bueyo Díez Jalón. La gobernanza local: hacia la transparencia y participación ciudadana en el funcionamiento de las administraciones locales. Revista General de Derecho Administrativo, 21, 2009.

[31] Marta Tarragona Gorgorió Josep María Pascual Esteve. Estrategia territorial y Gobierno Relacional. Consejería de Gobernación, Junta de Andalucía, 2009.

[32] Tomás Quintana López. El derecho de los vecinos a la prestación y establecimiento de los servicios públicos municipales en la jurisprudencia. Westlaw, Repertorio de jurisprudencia, 5, 2007.

[33] Santiago Muñoz Machado. Ilusiones y conflictos derivados de la directiva de servicios. Revista General de Derecho Administrativo, 21, 2009.

[34] Gérard Marcou. El alcance y la naturaleza de las competencias de las Entidades Locales en los Estados miembros del Consejo de Europa. Informe para el Comité Director para la Democracia Local y Regional del Consejo de Europa. Ministerio para las Administraciones Públicas, 2006.

[35] Adrian Moore. Putting out the trash: measuring municipal service efficiency in u.s. cities. Reason Public Policy Institute, 2003.

[36] Luis Ortega. Régimen local y estatutos de autonomía. Revista de Estudios de la Administración local y autonómica, 300-301, 2006.

[37] Antonio Serrano Pascual. El régimen jurídico de los funcionarios con habilitación de carácter estatal. El Consultor, 3, 2009. 
[38] Antonio Natera Peral. La gobernanza como modo emergente de gobierno y gestión pública. Revista de Gestión y Análisis de Políticas Públicas, 33-34, 2005.

[39] José Ignacio Morillo-Velarde Pérez. Las competencias municipales en materia de prevención social. Revista Andaluza de Administración Pública, 2008.

[40] Programa de las Naciones Unidas para los Asentamientos Humanos. Directrices obre descentralización y fortalecimiento de las autoridades locales, 2007.

[41] Programa de las Naciones Unidas para los Asentamientos Humanos. International guidelines on access to basic service for all, Nairobi, 2009.

[42] Daniel Sarmiento Ramírez-Escudero. El principio de la proporcionalidad y la defensa de la autonomía local. Revista de administración pública, 162, 2003.

[43] Joshue Cooper Ramo. The age of the unthinkable. Hachette Book Group, 2009.

[44] Robert B. Reich. Supercapitalism. The Transformation of Business, Democracy, and Everyday Life. Alfred A. Knopf, 2007.

[45] Marc Vilalta Reixach. El Gonsejo de Gobiernos locales. IUSTEL, 2007.

[46] Federico Revelli. Spend more, get more? an inquiry into english local government performance. Universitá de Torino, working papers series, 4, 2008.

[47] Sonia Rodríguez-Campos. Las reglas del mercado libre y su proyección en la realidad jurídica y económica. Revista española de Derecho Administrativo, 142, 2009.

[48] Franz Xavier Barrios Suvelza. Conceptos alternativos para comprender las grandes reformas descentralizadoras contemporáneas en europa occidental. Revista de Estudios Políticos, 144, 2009.

[49] J. Ramón Parada Vázquez. La segunda descentralización: del estado autonómico al municipal. Revista de Administración Pública, 172, 2007.

[50] Francisco Sosa Wagner. La gestión de los servicios públicos locales. Thomson Civitas, 2008.

[51] Ciudades y Gobiernos Locales Unidos. Primer informe global sobre la descentralización y la democracia local en el mundo (informe gold). 2007.

[52] Francisco Toscano Gil y Marc Vilalta Reixach. El consejo andaluz de concertación local: una oportunidad perdida para la autonomía local en Andalucía. Revista Andaluza de Administración Pública,70, 2008. 